\title{
Numerical Modelling to Predict Fracturing Rock (Thanet Chalk) due to Naturally Occurring Faults and Fluid Pressure
}

\author{
Kenneth Imo-Imo Eshiet ${ }^{1}$, Michael Welch ${ }^{2}$ and Yong Sheng ${ }^{3}$ \\ ${ }^{1,3}$ School of Civil Engineering, University of Leeds, LS2 9JT, Leeds, UK \\ ${ }^{2}$ Centre for Oil and Gas, Technical University of Denmark, Elektovej, 2800 Kgs. Lyngby \\ (E-mail: ${ }^{1}$ cnkiie@leeds.ac.uk, ${ }^{2}$ mwelch@dtu.dk, ${ }^{3}$ y.sheng@leeds.ac.uk,
}

\begin{abstract}
The fracturing process within the subsurface environment is often affected by pre-existing features such as naturally occurring faults. The interaction between these features and the propagating fractures together with their response to fluid pressure perturbations are multifaceted and in many instances not well understood. Faults play a major role in the containment of fractures and (depending on their size, configuration and mechanical properties) may instigate initiation of fractures. Outcrop mapping of a chalk cliff and wavecut platform in Thanet, Southeast England show a complex fracture pattern that seems to be controlled by meso-scale strike-slip faults within the chalk. The response of these faults to changes to in situ stress and fluid pressure is thought to control the nucleation and propagation of fractures in the chalk. In this study the DEM (Discrete Element Method) technique has been employed as a follow up to previous field and numerical (boundary and finite element method) investigations to ascertain the role of the faults in the initiation and nucleation of fractures, as well as their role in expediting or constraining further fracture proliferation. The role of fluid pressure, in-situ stress, and fault geometry are recognised as focal factors. Two fault geometries were studied: a strike-slip fault containing a releasing bend and a strike slip fault containing a restraining bend. The generation of localised areas of tensile stresses due to fluid pressure and stress perturbations have been shown to cause the initiation of fractures around the fault bends. Although this phenomenon occurs for both fault geometries, the location of the highest fluid pressure and initiation of fracture is different in each case. The dissimilarity in the fracturing process due to differences in the geometry of pre-existing faults demonstrates the significance of both fault geometry and fluid behaviour in controlling fracturing.
\end{abstract}

Keywords: Discrete Element Method; Fracture; Fluid Pressure; Faults; Subsurface; Chalk

\footnotetext{
3 Corresponding Author:

Address: School of Civil Engineering, University of Leeds, UK

e-mail: y.sheng@leeds.ac.uk
} 


\subsection{Introduction}

Discontinuities within a rock mass could occur due to non-homogeneity, naturally occurring faults, artificially induced fractures, folds and stratification. Some aspects involving the role of discontinuities in the general fracturing process have been studied (e.g., Hofmann et al., 2016, Singhal and Gupta, 2010, Mahrer et al., 1996). Discontinuity is a general term that connotes shear bands, fractures, joints, faults, cleavages, foliations, bedding planes, unconformities, intrusive contacts, etc. (Singhal and Gupta, 2010). Layering and changes in material properties can also be regarded as discontinuities.

Genetically, fractures are distinguished under three categories: shear, dilational and hybrid fractures (Singhal and Gupta, 2010). The increase in complexity in fracture morphology due to the presence of natural flaws and planes of weakness, as indicated by Mahrer et al. (1996), served to create a paradigm shift from the earlier overly simplified concept of a single fracture propagation from wellbores. While evaluating the potential for an increase in geothermal and hydraulic efficiencies by a plexus of fractures, the development of complex fracture networks has also been shown by Hoffmann et al. (2016) to be majorly influenced - amongst other factors - by complex tectonic architectures comprising natural discontinuities including faults, fractures and bedding planes. Artificially created discontinuities embedded in homogeneous rocks have been used by Blair et al. (1989) to demonstrate the distortions in fracture propagation patterns as they encounter and exit a discontinuity. Blair et al. (1989) noted that the break in the trend of fracturing is signified by a jump in fluid pressure records as the fracture interacts with the interface.

Investigations pertaining to specific types of discontinuities reveal individual peculiarities. Preexisting fractures, whether naturally occurring or induced by human operations are the most rampant discontinuities, hence, easily encountered. Some studies (e.g., Dehghan et al., 2017, Chen et al., 2016, Zhang and Fan, 2016, Wang et al., 2016, Yushi et al., 2016, Hofmann et al., 2016, Tiegang et al., 2014, Chuprakov et al., 2013, Casas et al., 2006), have shown the intricate mechanisms that govern interactions between discontinuities and propagating hydraulic fractures. Analytical and numerical analyses have been employed by Chen et al. (2016), Chuprakov et al. (2013) and Dehghan et al. (2017) to explore the crossing mechanism and the evolution of both hydraulic fracture geometry and injection pressure during interactions between hydraulic fractures and natural fractures. Several contributing factors were underscored including the interfacial shear strength of the natural fractures, in-situ stresses, intersection angles, initial conductivity and apertures of the natural fractures (or preexisting fractures), injection rate, fracturing fluid viscosity and energy release rate. Amongst the influencing factors, Zhang and Fan (2016) suggests that the injection rate and density of natural fractures have the most domineering effect on fracture network. As indicated by Dehghan et al. (2017), the energy release rate affects the propagation behavior of the hydraulic fracture at the point 
of intersection and is dependent on the in-situ stress differential, and the strike and dip of the natural fracture. In coal seams, cleats - as demonstrated by Teigang (2014) - determine the point of initiation and propagation paths of hydraulic fractures.

The presence of silty laminae in shale formations generally improves the storage capacity (via an increased porosity) and conductivity (Lei et al., 2015). In naturally fractured shale formations comprising silty laminae, the propagation of hydraulic fractures and their interactions with natural fractures are influenced by laminae strength (Lei et al., 2015). The combination of medium laminae strength, a high injection rate and a low in-situ stress ratio is shown by Wang et al. (2016) to increase stimulated reservoir volume (SRV) as well as the hydraulic conductivity arising from an improved fracture network. Even in normal shale formations, the injection rate and in-situ stress differentials affect the fracture network resulting from connections between hydraulic and natural fractures (Yushi et al., 2016). In Cases et al. (2006), joint fills are shown to play a major role in determining the fate of approaching fractures. Highly viscous elastic fills, similar to clay-rich materials, tend to facilitate fracture arrest due to their viscoelastic properties.

Other specific cases involving layered formations have also been considered (e.g., Liu et al., 2016, Escobar et al., 2016, Guo et al., 2016a, Lu et al., 2015, Philipp et al., 2009, Athavale and Miskimins, 2008, Daneshy, 1978, Simonson et al., 1978). Fracture morphology become complex at the interface between layers due to contrasting stress and material properties (Escobar et al., 2016, Guo et al., 2016a, Liu et al., 2016, Philipp et al., 2009, Athavale and Miskimins, 2008, Simonson et al., 1978) and this phenomenon is common in laminated formations (Athavale and Miskimins, 2008). Fractures are mostly arrested at interfaces between layers, especially where there is a contrast in mechanical properties (Philipp et al., 2009). The strength of the interface influences fracture containment (Daneshy, 1978). When the bond between rock layers is strong, it allows for an easier propagation of fractures across the interface. Weak interfaces are inclined towards constraining fracture propagation. There is evidence to show (Escobar et al., 2016, Guo et al., 2016a, Simonson et al., 1978) that fracture is constrained if the tectonic stress in the target layer is lower than the adjacent layer and a contrary effect applicable where the stress is higher. The greater the critical stress intensity factor, the higher the required fracturing fluid pressure and the shorter the extent of fracture propagation (Escobar et al., 2016). In addition, fracture growth is limited by a layer of lower elastic modulus and high tensile strength (Guo et al., 2016a). Stresses usually concentrate in stiff layers, which, either promote fracture migration if the stresses are tensile or serve as a barrier if the stresses are compressive (Philipp et al., 2009).

With respect to interactions between faults and fractures, the effect of faults on the general fracturing mechanism is crucial. Some studies have analysed the role of faults, fluid pressure and in-situ stresses on fracture development (e.g., Eshiet and Sheng, 2016, Chen et al., 2016, Eshiet and Sheng, 2015, 
Ghorashi and Monghad, 2015, Yang and Zoback, 2014, Shakib et al., 2013, Chuprakov et al., 2010, Singhal and Gupta, 2010, Hilley et al., 2001, Peacock, 2001, Bourne and Willemse, 2001, Rawnsley et al., 1998, Rawnsley et al., 1992). The propensity for the development of tensile (open-mode) fractures at close proximity to faults due to fault-induced stress perturbation is illustrated in Chuprakov, et al. (2010), Bourne and Willemse (2001), Rawnsley, et al. (1998) and Rawnsley, et al. (1992). Analyses by Chuprakov, et al. (2010) regarding the stress state along a natural fault at various stages of hydraulic fracturing show the development of tensile stresses tangential to the fault, leading to the generation of primary and secondary tensile fractures. This phenomenon was earlier observed by Borne and Willemse (2001), where fault slippage due to stress loads was reported to cause an increment in local tensile stresses close to the fault; remote loading initiated a predominance of tensile (open-mode) fractures but these proliferated due to the stress perturbations by the faults. According to Rawnsley, et al. (1998, 1992), the surroundings of faults are strongly agitated as compared to far-field zones. Joints propagate from unperturbed to perturbed regions of stress field. Stress field perturbations could be caused by locations of high friction along the fault plane, which result in stress concentrations and a coalescence of joints at such areas. Joints that are disturbed by faults, propagate towards areas of high stress concentrations and can therefore be used as footprints for stress field perturbations.

The work presented here forms part of the assessment carried out to investigate the local stress developed around large faults as a result of regional tectonic strain, fault slip and fluid overpressure; with the intention of establishing the main factors controlling the initiation, distribution and orientation of fractures around pre-existing subsurface faults. In this paper, we investigate the impact of fluid pressure on fracture development. Previous work has suggested that the fracturing process in chalk is often governed by changes in fluid pressure, which also affect stress distributions (Welch et al., 2015). Before fracture initiation, the build-up of pore fluid pressure alters the local stress field by reducing effective stresses, thereby leaving the matrix more prone to tensile failure. It can also trigger slip on the faults, generating local stress concentrations around fault bends and tips. During fracturing, dilation of the fracture as well as fluid pressure on the fracture wall cause additional perturbations of the local stress field and affects the fracture orientation.

\subsection{Review of DEM Techniques}

DEM techniques have been used to study the structural dynamics of faults. Abe et al. (2011) used DEM models to simulate the formation of normal faults in a brittle-cohesive material representative of hemihydrate powder $\left(\mathrm{CaSO}_{4} \cdot 1 / 2 \mathrm{H} 2 \mathrm{O}\right)$. Results obtained were similar to field observations and sandbox experiments (analogue models) performed by Holland et al. (2006), van Gent et al. (2010) and Holland et al. (2011). A DEM approach was applied by Schopfer, et al. (2007a) to represent the 
dynamic structure of normal faulting systems in layered sequences such as changes in fault dip due to variations in failure modes, fault bifurcation, the occurrence of normal drag and the connection of fault segments. An extension of this model, in Schopfer, et al. (2007b), assessed the effects of strength contrast and confining pressure on the growth of normal faulting systems in layered sequences. DEM models have also been employed to simulate the structure of fault zones with respect to the impact of confining pressure, sequence and fault obliquity (Schopfer et al., 2016); to examine the influence of loading rate on the seismicity generated by faults intruded by salts or other ductile materials and the contributions of these infills to the fault dynamic behaviour (Urai et al., 2016); and to measure the behaviour of pipe joints during normal and reverse fault movements (Kuwata et al., 2007).

Rock fracturing phenomena are effectively modelled by DEM methods. DEM models have been used to, for instance, investigate fracture initiation from circular rock cavities (Tarokh et al., 2016), determine interactions between natural fractures and induced hydraulic fractures (Zhou et al., 2016), mimic hydraulic fracturing (Eshiet et al., 2012) and rock fragmentation (Chi et al., 2015), and assess the effect of macroporosity - holes in rock - on fracture pattern and rock tensile strength (Bai et al., 2016). In addition, various formulations of DEM techniques have been employed to study fracture behaviour by simulating typical laboratory based experiments used for determining rock fracture and strength properties. Well known experiments adopted for DEM investigations are the three-point bending test (Fakhimi and Wan, 2016, Xu et al., 2016, Guo et al., 2016b) and the indentation test (Andre et al., 2013).

\subsection{Coupling DEM and fluid flow}

There are some advancements in coupling techniques linking DEM, fluid flow and heat transfer. For instance, the fluid-mechanically coupled model developed by Cundall (2000) has been further modified by Zhou, et al. (2016), incorporating additional functions to account for the variability in exerted fluid pressure due to partial saturation and the inconsistencies in pore sizes of porous rock. The modified approach has been used to model the breakdown pressure during the hydraulic fracturing process under various in-situ stress conditions. Improved ways (the centre void fraction method and the divided void fraction method) of calculating the void fraction within a fluid cell in a coupled computational fluid dynamics (CFD)-DEM scheme is presented in Zhao and Shan (2013), where fluid flow is solved by the locally averaged Navier-Stokes equation using fluid cells (grids). In the centre void fraction method, the total volume of a particle is included in the calculation of the void fraction of a cell if the centre of the particle is located within the same cell. In the divided void fraction method, only the overlapping portion of the particle is accounted for using the contributing volume or weight of the particle (via a weighted ratio) relevant to the fluid cell. A similar CFD-DEM configuration is applied in Ghani et al. (2013) to model hydraulic fracturing by overlapping a DEM lattice with a continuum fluid grid used to solve a Darcy-based Navier-Stokes equation for pore- 
pressure diffusion. In this approach, Biot's poroelastic theory is applicable only in the linear elastic regime before fracture initiation. Beyond this point, Biot's Compressibility ceases to be valid. The dynamics of the fluid during the irreversible deformation of the rock matrix is modelled through the application of the Kozeny-Carman porosity-permeability relation.

Further developments involving the lattice Boltzman method (LBM) are given, for example, in Galindo-Torres (2013), Wang and Adhikary (2015) and Wang et al. (2015). Galindo-Torres (2013) introduced a new procedure for coupling the discrete element method (DEM) with the lattice Boltzman method (LBM) (Hecht and Harting, 2010) using a proposed coupling law. The uniqueness of this approach is promoted by the use of different shapes of DEM particles created through the application of the sphero-polyhedra method (Galindo-Torres et al., 2012, Galindo-Torres and Pedroso, 2010, Galindo-Torres et al., 2009, Alonso-Marroquin, 2008, Pournin and Liebling, 2005). A comprehensive hydro-thermal fluid-solid coupling technique is demonstrated in Tomac and Gutierrez (2017), while Wang and Adhikary (2015) and Wang et al. (2015) illustrate a two-way coupling of DEM and LBM to model hydraulic fracturing, porous flow and heat transfer in fractured rock masses.

An alternative way of building a rock matrix is by replacing the particle assembly with a collection of jointed blocks. This is exercised in Gentier, et al. (2012) for the DEM simulation of hydraulic fracturing in geothermal wells. In Gentier, et al. (2012), the rock matrix is impermeable, deformable and consists of an assembly of tetrahedral elements (blocks). Fluid flow only occurs through fractures. The flow is laminar (obeying a cubic law) and the joints (contacts) are fully saturated. Fractures are discretised into elementary domains and the pressure within the domains are updated during the inflow or outflow of fluid. This causes a change in the stress applied to the surrounding material which may in turn cause changes in the dilation of the fracture and the pressure distribution. Fracture dilation results in an increase in permeability.

The coupling of DEM and fluid flow is also applicable to phenomena involving low particle-fluid ratio. The Darcy-based Navier-Stokes equation (for pressure) has been coupled with Newton's second law (for the grain dynamics) and used to simulate granular Rayleigh-Taylor instabilities involving a mixture of grain and air mass (Vinningland et al., 2007). Permeability is calculated using the CarmanKorzeny relation. Also, a formulation for calculating changes in pore fluid pressure and the liquefaction of fluid-filled granular material due to its loss of strength is given in Goren et al. (2010) and Goren et al. (2011).

\subsection{A compendium of the previous numerical investigations}

Previous Boundary Element Modelling (BEM) and Finite Element Modelling (FEM) studies (Welch et al., 2015) indicate that complex fracture patterns will develop around meso-scale faults due to 
concentrations of localised stress. This work showed that localised high intensity fracture patterns such as concentric rings of fractures will develop around fault bends, tips and splays under normal fluid pressure conditions, but that high fluid overpressure will generate fracture corridors that nucleate along the faults but then propagate away from them, often linking up with adjacent faults. Numerical studies have hence been conducted to establish the controlling factors that influence the location and orientation of fractures, to enable the determination of guidelines for predicting the pattern of fracturing around the faults in chalk.

The presence of meso-scale size faults in the chalk in Thanet is described in Shepherd-Thorn (1988). Field mapping showed these to have metre-scale displacement and to strike predominantly NNW-SSE, but with numerous small bends, relays and splays (Souque et al., (in review)). Boundary element models (also sometimes known as elastic dislocation models) were applied to study the local stress distributions around these bends, tips and splays under normal fluid pressure. With the boundary element model, the fault is discretised into a number of planar "panels". The fault displacement on each panel is specified as an input initial boundary condition which is subsequently used to derive stress fields, strain fields and equilibrium displacements in the surrounding chalk, which is assumed to be a homogeneous elastic medium (Okada, 1992, Healy et al., 2004). The major distinctive features of the boundary element model are that the fault is discretised rather than the surrounding rock mass, and the requirement of fault displacements instead of stress as initial boundary conditions. This makes them quick and easy to run but makes it difficult to simulate the effects of fluid overpressure. It was found that the stress pattern predicted by boundary element models matched the geometry of many of the localised fracture patterns observed around the tips, bends and splays of the faults in Thanet, but could not match the fracture corridors that were also observed here (Welch et al., 2015).

Finite element models have also been applied in studying nucleation of fractures as a result of slip on the faults mapped in Thanet. In finite element models, the rockmass is discretised rather than the faults. Faults and fractures are represented as surfaces that can experience sliding friction or loading forces (potentially causing dilation). It is thus possible to model the effects of fluid pressure within the faults and fractures by altering the loading forces on these surfaces to reflect a direct application of stress to the fault and fracture walls. Pore fluid overpressure in the surrounding rockmass can also be portrayed by assigning a tensile stress boundary condition to the outer edge of the model, simulating the case where the pore fluid pressure $\mathrm{P}_{\mathrm{f}}$ is greater than the absolute minimum horizontal stress $S_{\text {hmin }}$. Unlike in BEMs, in FEMs the fault displacements are calculated automatically as a function of the boundary stresses. Local stress, strain and displacement are then calculated throughout the discretised chalk rockmass. At normal fluid pressures, the stress patterns predicted by FEMs are identical to those predicted by BEMs, but at high fluid overpressure (where $\mathrm{P}_{\mathrm{f}}>\mathrm{S}_{\mathrm{hmin}}$ ) the stress pattern changes dramatically and a large tensile stress anomaly develops at the propagating fracture tip. 
Although the BEM and FEM methods can both predict stress distributions which are similar to fracture geometries observed in the field, they both have limitations. Neither of the methods rigorously account for the effect of fluid pressure; even the FEM can only incorporate static (constant) fluid pressure, and hence cannot account for fluid flow along the fractures, pressure drop due to fracture dilation and propagation or fluid leak-off, all of which are key controls on fracture propagation (Pollard and Muller, 1976, Secor Jr and Pollard, 1975, Pollard, 1973, Nordgren, 1972, Weertman, 1971). Furthermore BEMs and FEMs do not directly simulate fracture propagation, and so it is difficult for the models to account for the changing stress field due to growth of the fractures, which influences the direction of propagation as well as the point of initiation of new fractures. However the FEM model is able to simulate the stress system surrounding a static dilatant fracture as a result of the fluid pressure within the fracture and/or applied stress conditions. The previous FEM study (Welch et al., 2015) has taken advantage of this feature to model the propagation of fractures with a series of static models. In the first model, the stress field around a fault bend was calculated for normal or overpressured conditions. An initial seed fracture was placed at the point of maximum tensile stress, perpendicular to the local $S_{\text {hmin }}$ orientation. This fracture is then extended incrementally at the end of each succeeding model run; the extent and orientation of the increment is dependent on the local stress field around the fracture tip at the end of the previous run. These models show that a large tensile stress anomaly will develop at the tip of a dilatant fracture under overpressured conditions (but not at normal fluid pressure); this is sufficient to drive continued propagation of the initial fracture, and other parallel fractures, away from the fault where they nucleated, generating a fracture corridor. Similar results were obtained from a modelling study by Olson (2004). These models show that fluid overpressure is essential to generate fracture corridors.

In this study, a different approach is hereby introduced which captures the phenomenon of fracture propagation from the perspective of the interaction between particles of solid rock and the surrounding fluid. In the Discrete Element Method (DEM) the rock is represented as a combination of small spherical or spheroidal bonded particles. Brittle failure can be simulated by the breaking of interparticle bonds, creating cracks or shear surfaces. It should be noted however that the particles in the DEM are too large, by several orders of magnitude, to represent individual rock grains (especially in a fine-grained rock such as chalk); instead the measured bulk rock properties are matched by adjusting the elastic properties of the individual particles and the properties of the bonds between particles.

In the coupled DEM-fluid flow model, fluid inhabits the pore space between the particles, and can flow through the pore network in response to pressure gradients, especially when interparticle bonds are broken. In return the fluid pressure can itself break apart the bonds between adjacent particles to create fractures. We can thus use this model to accurately simulate the propagation of fluid-driven fractures in a porous medium. 


\subsection{Field observation and analysis}

Field mapping for this study has been carried out in Pegwell Bay, Kent, SE England (Figure 1), where a large expanse of chalk outcrop in a cliff section and along a horizontal wavecut platform enable a cross-sectional and horizontal (plan view) mapping of its structural components. This outcrop contains several meso-scale strike-slip faults and is heavily fractured, exhibiting both localised fracture patterns around fault bends, tips and splays and long fracture corridors (up to 100m length) connecting adjacent faults.

Pegwell Bay is situated on the steeper southern limb of the E-W trending Thanet anticline. The chalk dips at $c .7^{\circ}$ to the south here. A detailed description of the local and regional geology is given in Shepherd-Thorn (1988) and Ameen (1995a). The strike-slip faults strike c.NNW-SSE with dips ranging between $60^{\circ}$ to $90^{\circ}$. A substantial number of unfilled open fractures are observed in the outcrop, both close to and further away from these faults. Both the faults and fractures were mapped in detail by Souque et al. (in review) (Figure A1). Based on geometry, these are categorised as follows (Welch et al., 2015):

- Fracture corridors consisting of narrow zones (1-2m wide) with a high-density of closelyspaced $(1-10 \mathrm{~cm}$ spacing) subparallel fractures. These mostly nucleate at or adjacent to fault bends or tips but propagate away from to the faults by which they nucleated, rotating towards the orientation of the regional stress field. The fractures are open and unfilled, and are interpreted as Mode 1 dilational fractures.

- Concentric fracture rings, consisting of short closely-spaced (1-10cm spacing) semicircle-like concentric rings of fractures. They also tend to occur at the vicinity of fault bends, tips and splays but unlike the fracture corridors they do not propagate more than $1-2 \mathrm{~m}$ from their point of initiation. They are also unfilled, open and interpreted as Mode 1 dilational fractures.

This study is based on the field observation and mapping of the chalk outcrop at Pegwell Bay, Kent, SE England, consisting of several heavily fractured meso-scale strike-slip faults.

Because they comprise unfilled open fractures, the concentric fracture patterns may increase local permeability around the faults but are unlikely to be major fluid conduits. By contrast the fracture corridors, comprising long sub-parallel open fractures that extend for $10 \mathrm{~s}$ to $100 \mathrm{~s}$ of metres and connect adjacent faults, are likely to be significant fluid conduits. Understanding the controls on nucleation and propagation of these different fracture types is thus key to predicting the likely flow properties of the chalk in the subsurface. The DEM and embedded fluid flow model can dynamically 
reproduce the pressure perturbations, and fracture initiation and nucleation around sensitive fault areas allowing an identification of the key factors governing the unique behaviour of faults, especially at the vicinity of the same areas.
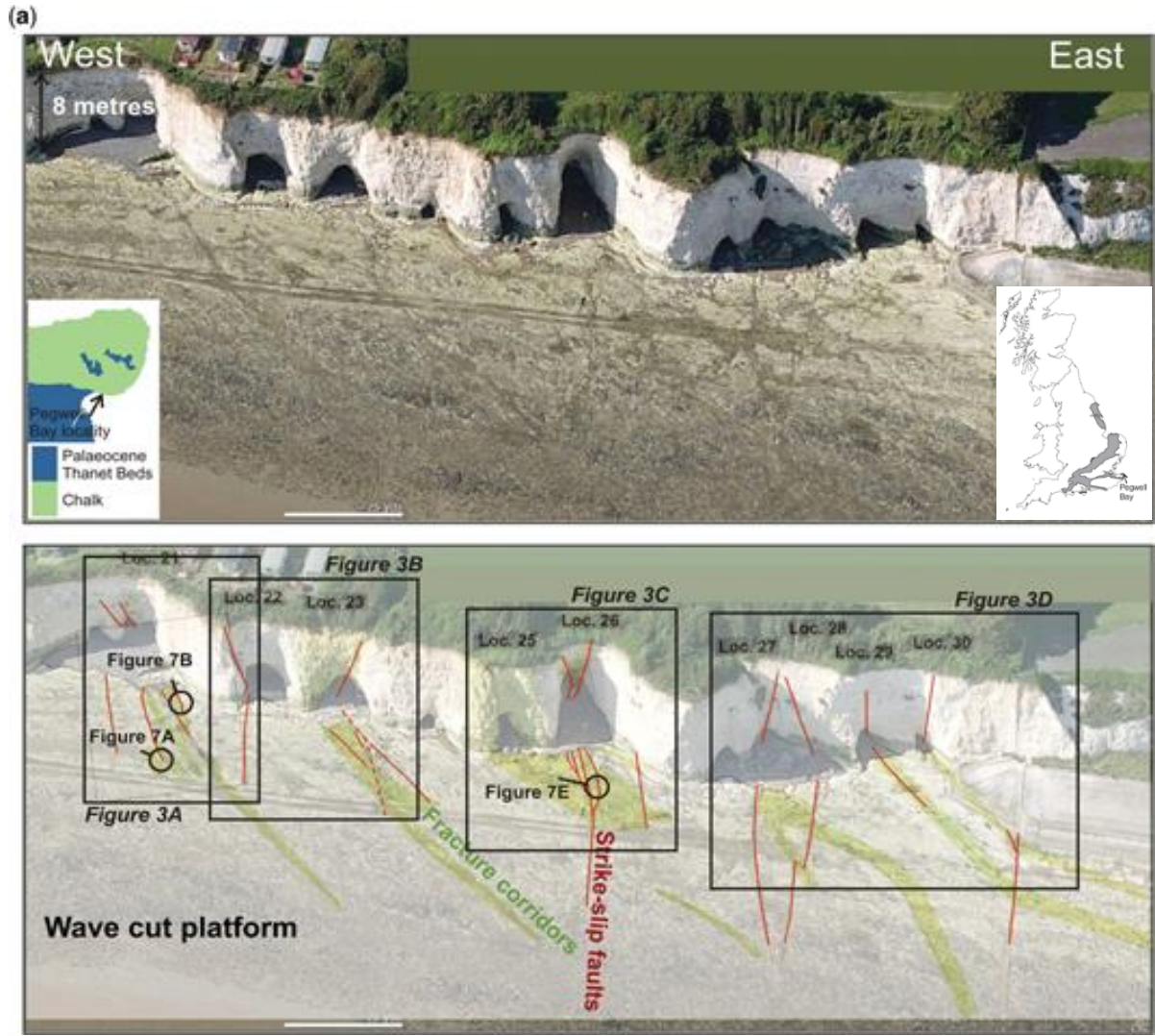

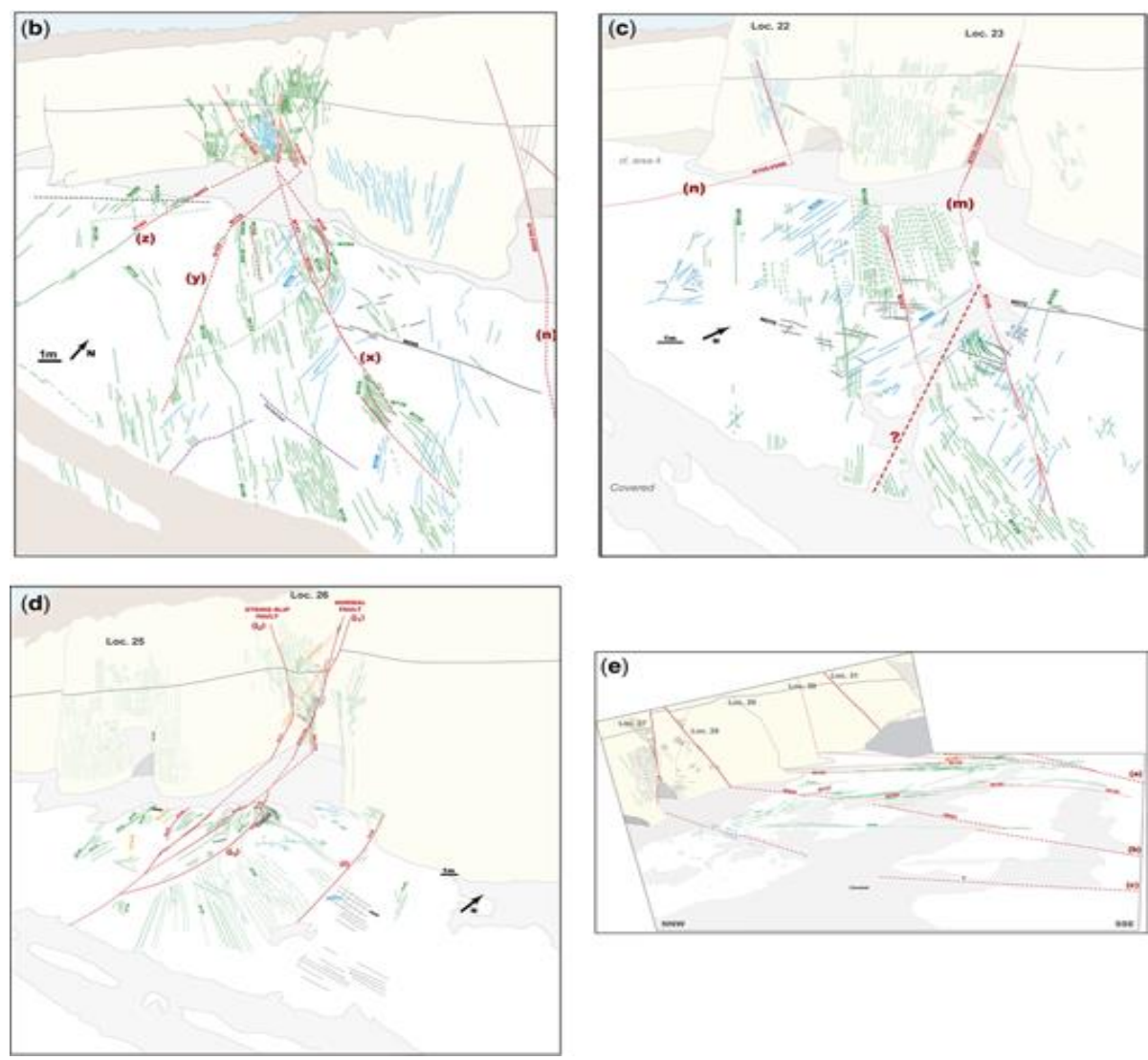

Figure 1. The Cliff-section and wave-cut platform at Pegwell Bay showing strike-slip faults (red lines) and fracture corridors (green shading) (Welch et al., 2015)

\subsection{Methodology}

The Discrete Element Method (DEM) allows the construction of particle assemblies where interaction occurs between particles through contacts. Bonds co-exist between each contacting particle and the weakening and subsequent breakage of the bonds signifies fracture initiation. The rock material is hence modelled as a bulk material comprising particles of prescribed stiffness that are attached together through normal and shear bonds. Mechanical calculations for the particle perturbation are based on the force displacement law that resolves the magnitude of shear and normal forces and the corresponding relative displacement at each contact, as well as the law of motion that controls the particle movement due to the resultant force and moment vectors acting on it.

Fluid flow is integrated within DEM via a fully coupled scheme comprising of a network of pressure reservoirs inter-connected by flow channels. This enables a dynamic simulation of flow, fractures and pressure distribution, which are regularly updated in the coupling process. The particle assembly created was calibrated such that the assigned micro-properties were representative of the target macroproperties of the rock mass. The fluid flow scheme was implemented by coupling the process with particle via mechanical interactions. The fluid flow micro-properties were also calibrated so as to 
mimic the characteristics of fluid flow behaviour at the macro-scale. Formulations and algorithms pertinent to the particle assembly and fluid flow are described in the appendix.

\subsection{Model description and results}

DEM models were run to simulate fracture nucleation and propagation around bends and tips in the meso-scale strike-slip faults mapped in Pegwell Bay.

Three models were run, representing three different fault geometries (Figure 2). In all models it was assumed that fracturing occurs at a depth of c. $2000 \mathrm{~m}$, and the chalk mechanical properties used are representative of chalk at that depth (Welch et al., 2015). All simulations were executed in 2D on horizontal planes, assuming plane stress conditions so that displacement on the faults is in the plane of the model. Models 3 and 4 comprised $20 \times 20 \mathrm{~m}$ square sections containing a fault oriented at $45^{\circ}$ to the model boundaries with a $0.6 \mathrm{~m}$ long bend in the centre (Figure $2 \mathrm{~b}-\mathrm{c}$ ). The model configuration, initial and boundary conditions, as well the rock material properties are described in the following sections.

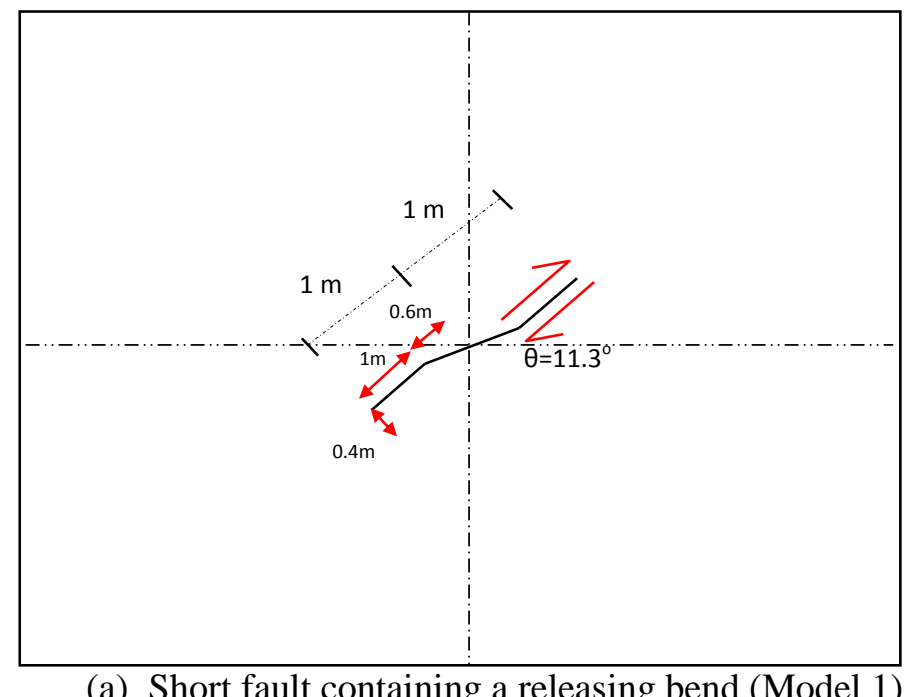

(a) Short fault containing a releasing bend (Model 1) 


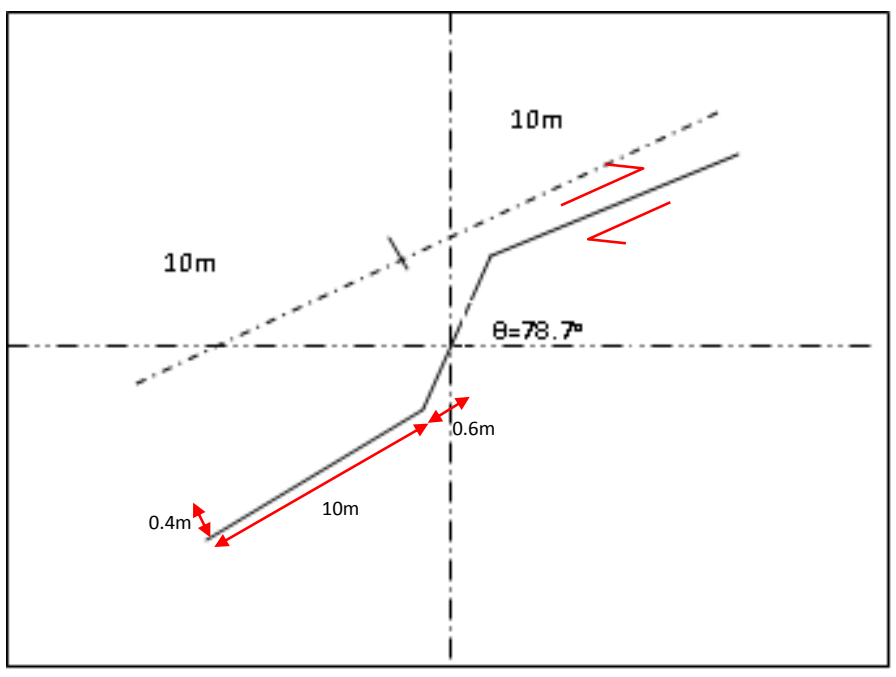

(b) Long fault containing a restraining bend (Model 2)

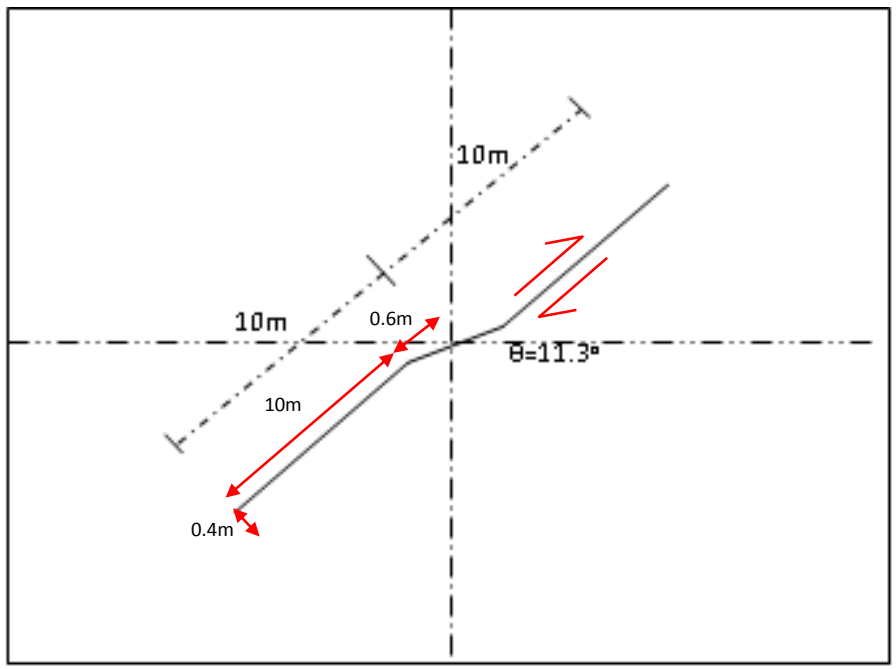

(c) Long fault containing a releasing bend (Model 3)

Figure 2. Schematic of model geometries

\subsection{Rock properties and boundary conditions}

Models were constructed in 2D plane stress displayed in plan views, which implies that faults and fractures can be subjected to strike-slip shear or dilatant in-plane displacement. The plane stress is taken as the vertical stress, equated to the lithostatic stress and assumed to be uniform and constant. The initial conditions consisted of externally applied stresses along the model boundaries representing the maximum and minimum horizontal principal stresses, which were kept constant. 
The rock properties were selected to be representative of chalk buried to a depth of $2000 \mathrm{~m}$ and compacted normally (Welch et al., 2015). They are listed in Table 1.

Table 1 Rock Properties

\begin{tabular}{c|c}
\hline \multicolumn{2}{l}{ Elastic Properties } \\
\hline Young Modulus, $E$ & $15 \mathrm{GPa}$ \\
\hline Poisson's ratio $\square$ & 0.3 \\
\hline Coulomb Plastic Properties \\
\hline Tensile strength, $T$ & $2.5 \mathrm{MPa}$ \\
\hline Cohesion, $S_{o}$ & $6.0 \mathrm{MPa}$ \\
\hline Onternal friction coefficient, $\mu$ & 0.3 \\
\hline \multicolumn{2}{c}{ Other properties } \\
\hline Porosity $\square$ & 0.17 \\
\hline Density $\square_{\mathrm{b}}$ & $2250 \mathrm{Kg} / \mathrm{m}^{3}$ \\
\hline
\end{tabular}

Table 2 Initial and Boundary Conditions

\begin{tabular}{c|c}
\hline \multicolumn{2}{l}{ External boundaries } \\
\hline $\begin{array}{c}\text { Maximum horizontal stress, } \\
\sigma_{\text {hmax }} \\
\text { (horizontal direction) }\end{array}$ & $15.0 \mathrm{MPa}$ \\
\hline $\begin{array}{c}\text { Minimum horizontal stress, } \\
\sigma_{\text {hmin }} \\
\text { (vertical direction) }\end{array}$ & $14.4 \mathrm{MPa}$ \\
\hline Total lithostatic stress, $\sigma_{v}$ & $34.4 \mathrm{MPa}$ \\
\hline Effective lithostatic stress, $\sigma_{v}$, & $14.6 \mathrm{MPa}$ \\
\hline Loading & $19.6 \mathrm{MPa}$ \\
\hline Final fracture fluid pressure, $P_{f}$ & \\
\hline Fluid properties & $1010 \mathrm{Kg} / \mathrm{m}^{3}$ \\
\hline \multicolumn{2}{c}{ Density, $\rho_{f}$} \\
\hline
\end{tabular}


The stress boundary conditions are selected to be representative of a rock at $2000 \mathrm{~m}$ burial depth, subject to a strike-slip strain such that the maximum horizontal strain $\varepsilon_{\text {hmax }}$ is compressive and the minimum horizontal strain $\varepsilon_{\text {hmin }}$ is tensile, and there is no volumetric strain (i.e. $\varepsilon_{\text {hmax }}=-\varepsilon_{\text {hmin }}$ ). The horizontal stress boundary conditions are calculated as follows.

The lithostatic stress is the total vertical component of stress or overburden pressure acting at any given depth. For an unsaturated rock mass, the lithostatic stress at any depth is defined as

$$
\sigma_{v}=\int_{0}^{h}(1-\phi(h)) \rho_{s} d h
$$

Where, $h$ is the subsurface depth of interest, $\phi$ is the porosity and $\rho_{s}$ is the particle density. If the rock mass is fully saturated, two additional force components are generated: the fluid pressure of the fluid in the rock pores and a corresponding buoyancy force as this fluid exerts an upward pressure. In a normally pressured reservoir, where the pore fluid pressure is equal to the weight of the overlying fluid, the corresponding stress components denoting these are

$$
\begin{gathered}
P_{p}=\rho_{f} g h \\
\sigma_{b}=-\int_{0}^{h}(1-\phi(h)) \rho_{f} g d h
\end{gathered}
$$

Where, $P_{p}$ is the pore fluid pressure and $\sigma_{b}$ is the upward buoyancy pressure expressed as negative due to the upward direction. For a saturated rock mass, the total lithostatic stress is hence expressed as the net overburden stress acting vertically downwards, obtained by combining Equations 1-3.

$$
\begin{gathered}
\sigma_{v}=\int_{0}^{h}(1-\phi(h)) \rho_{s} d h+\int_{0}^{h} \rho_{f} g h-\int_{0}^{h}(1-\phi(h)) \rho_{f} g d h \\
\sigma_{v}=\int_{0}^{h}(1-\phi(h)) \rho_{s} d h+\int_{0}^{h} \phi(h) \rho_{f} g d h
\end{gathered}
$$

The bulk density accounts for both the particle (rock) density and fluid density. It changes with depth since it is dependent on porosity and can be incorporated in Equation 4 to give 


$$
\sigma_{v}=\int_{0}^{h} \rho_{b}(h) g d h
$$

Total lithostatic stress typically does not increase linearly with depth since the porosity of most rocks (especially chalk) decreases with depth, due to compaction in response to increasing lithostatic stress (see e.g., Mallon and Swarbrick, 2002). At a depth of 2000m a typical total lithostatic stress would be 34.4MPa and a typical hydrostatic fluid pressure 19.8MPa (Welch et al., 2015).

The effective lithostatic stress $\left(\sigma_{v}\right)$ includes the effect of buoyancy since buoyancy forces acting through the contacts between particles in addition to the weight of the particles. The effective lithostatic stress is therefore determined by subtracting the fluid pressure, given as

$$
\sigma_{v}^{\prime}(h)=\sigma_{v}(h)-\sigma_{f}
$$

Since these models are horizontal plane stress models, the lithostatic stress is not applied explicitly as a boundary condition, but is assumed to be uniform and constant across the model. However the lithostatic stress will also induce horizontal stresses which must be applied as normal compressional stress loads acting on the boundaries of the model. In a strike-slip environment the horizontal stress will be anisotropic, with maximum and minimum horizontal stresses $\left(\sigma_{h \max }\right.$ and $\left.\sigma_{\text {hmin }}\right)$ at $90^{\circ}$ to each other.

\subsection{Modelling procedure}

The models were aligned so that the minimum and maximum horizontal stresses were orthogonal to the model boundaries. Stresses were applied to the external boundaries in the $\mathrm{x}$ and $\mathrm{y}$ directions: the maximum effective horizontal stress, $\sigma_{\text {hmax }}$ was applied in the x direction and the minimum effective horizontal stress, $\sigma_{\text {hmin }}$ was applied in the y direction. These were kept constant throughout. The external horizontal stress loads denote the effective maximum and minimum horizontal stresses assuming a total lithostatic vertical stress of $34.4 \mathrm{MPa}$. In these models we apply an anisotropic horizontal stress field with $\sigma_{\text {hmax }}=15.0 \mathrm{MPa}$ and $\sigma_{\text {hmin }}=14.1 \mathrm{MPa}$, giving a stress ratio $\sigma_{\text {hmax }} / \sigma_{\text {hmin }} \approx 0.96$. The pore fluid pressure $\mathrm{P}_{\mathrm{p}}$ is assumed to be hydrostatic, at $19.6 \mathrm{MPa}$. These values are listed in Table 2.

Since the fault is represented in the model as a free (unbonded) surface oblique to the minimum and maximum horizontal stress, applying the horizontal stresses to the boundary will cause the fault to slip. This will generate local stress concentrations, especially around the tips and the bend in the centre of 
the fault. With these boundary conditions in place, we assume that fracturing is triggered by the injection of a high pressure pulse of fluid along the fault. The fault fluid pressure Pf represents the excess fluid pressure (or overpressure) in the fault above the initial pore pressure Pp, although as high pressure fluid from the fault leaks off into the pores of the surrounding rock, the pore pressure may increase over time. In these models the initial fracture fluid pressure was set at zero and then explicitly and incrementally increased until an upper limit value of 19.6 MPa was attained. This upper limit fluid pressure value pertains to an overpressured condition, in which the host rock pores away from the fault core are under a hydrostatic pressure of 19.6 MPa while the fault is subjected to a total fluid pressure of $39.2 \mathrm{MPa}$.

Table 3 Description/Dimension of initial fault

Model 1

Model 2

\section{Model 3}

Short fault with

releasing bend
Long fault with restraining bend
Long fault with restraining bend

\section{Dimension}

Length of upper segment

Length of lower segment

Inclination of upper and lower segment

Bend (offset)

Inclination of bend

Region of fluid application

$\begin{array}{ccc}1 \mathrm{~m} & 9.7 \mathrm{~m} & 9.7 \mathrm{~m} \\ 1 \mathrm{~m} & 9.7 \mathrm{~m} & 9.7 \mathrm{~m} \\ 45^{\circ} & 45^{\circ} & 45^{\circ} \\ 0.6 \mathrm{~m} & 0.6 \mathrm{~m} & 0.6 \mathrm{~m}\end{array}$
$11.3^{\circ}$ to
horizontal axis
$11.3^{\circ}$ to
vertical axis
$11.3^{\circ}$ to
vertical axis

\begin{tabular}{ccc}
$\begin{array}{c}\text { Full length of } \\
\text { fault }\end{array}$ & $\begin{array}{c}\text { Middle section } \\
\text { of fault }\end{array}$ & $\begin{array}{c}\text { Full length of } \\
\text { fault }(20 \mathrm{~m})\end{array}$ \\
$(3 \mathrm{~m})$ & $(3 \mathrm{~m})$ & \\
\hline
\end{tabular}




\subsection{Results}

Three models were run with different fault geometries: the first comprising a short fault containing a releasing bend, the second comprising a long fault containing a restraining bend, in which fluid overpressure was applied to the central section of the fault, and a third with identical fault geometry but with fluid overpressure applied along the entire fault (Table 3).

\subsubsection{Model 1: Short fault with releasing bend}

This model represents a releasing bend in a short strike-slip fault. A releasing bend bends away from the direction of displacement, creating a zone of extension (Figure 2a).

\subsubsection{Model description}

The model dimension is given as $20 \mathrm{~m} \times 20 \mathrm{~m}$. The total length of the fault is just $2.4 \mathrm{~m}$ consisting of 3 segments: a lower fault segment, $1 \mathrm{~m}$ long and inclined at $45^{\circ}$; a releasing bend segment situated at the centre of the model, inclined at $11.3^{\circ}$ to the horizontal axis and $78.7^{\circ}$ to the vertical axis, with length $0.72 \mathrm{~m}$ and an upper fault segment, $1 \mathrm{~m}$ long and also inclined at $45^{\circ}$. All other parts of the model comprise homogeneous chalk. The assumption of homogeneity is contextual and relative. The surrounding sections of the rock are considered relatively homogeneous in comparison to the mesoscale size faults. Field observations do not show large asperities that influence the fracturing process at the neighbouring areas of the fault. The schematic of the fault geometry is shown in Figure $2 \mathrm{a}$. Because the fault is short, only a small amount of strike-slip displacement will occur in response to the applied horizontal stress, and the stress anomalies around the fault will be correspondingly small.

The host rock was initially assigned a low permeability (consistent with typical permeabilites in intact chalk; see Megson and Hardman (2001)) but becomes more permeable as the occurrence of fractures created inter-connecting pore spaces. As earlier stated, the initial fluid overpressure applied to the fault was zero, which was gradually increased in increments of $2 \mathrm{MPa}$ to a maximum of $19.6 \mathrm{MPa}$. The fault fluid pressure is applied simultaneously along the entire length of the fault. Figure 3 and 4 depict the rock mass highlighting the fault zone and the region where fluid overpressure was applied, respectively.

\subsubsection{Model results}


Cracking did not occur until after the maximum fluid pressure was applied. Propagation of fluid overpressure away from the fault also took place at this time as more flow channels between pressure domains were created in addition to the expansion of existing channels. It may therefore be implied that the condition of overpressure must be attained prior to failure and successive fracturing of the rock, though the dependency on time has not been rigorously checked at this stage of the investigation. Except Figure 3, all other figures are displayed as zoomed sections in order to clearly capture activities within the red outlined box (Figure 3). The pressure distribution, at the vicinity of the fault, after the limiting value of $19.6 \mathrm{MPa}$ is applied is shown in Figure 3-4b. The process is presented in a chronological order following the subjection of the fault plane to the maximum fluid pressure. The size of the brown circles represents the magnitude of the fluid overpressure relative to the initial pore fluid pressure.

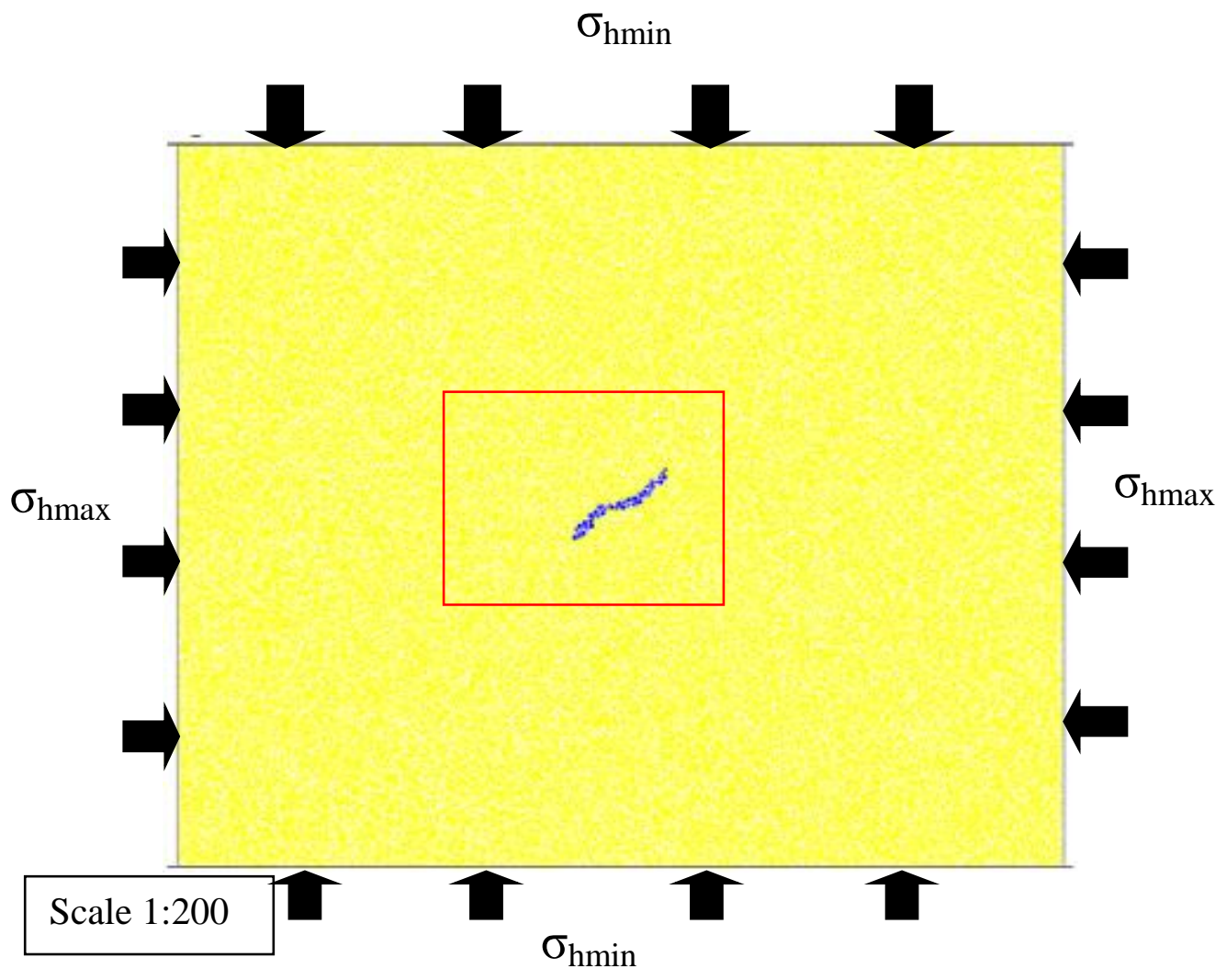

Figure 3. Initial state of rock mass (represented by yellow circles) indicating the fault zone (shown in blue). The red box marks the area shown in close up in Figure 4-5. 
The stress perturbation around the fault resulted in fluctuations and redistribution of fluid pressure. This caused higher concentration of pressure particularly near the fault tips. Figure $4 \mathrm{~b}$ and $4 \mathrm{c}$ illustrate instances of this, with apparently greater pressure intensities in the lower fault segment. An interpretation of this phenomenon indicates a gradual weakening of the material surrounding the fault tips due to higher stresses within these areas. As shown in Figure 5a fracture initiation occurred due to tensile failure (represented by red dash lines in the figure) within proximity of the fault tips. The mode of fracturing changes and becomes dominated by shear induced failure (represented by black dash lines in the figure) as the fracture propagates away from the faults (Figure $5 \mathrm{~b}$ and $5 \mathrm{c}$ ). Fracture propagation is asymmetric, occurring mostly on the left hand side of the lower fault segment. This is in the "tensile quadrant" where we would expect local tensile stress to be generated by right lateral displacement on the fault. There is very little fracturing around the fault bend, possibly as a result of the low fault displacement which generates only a small stress concentration around the bend.

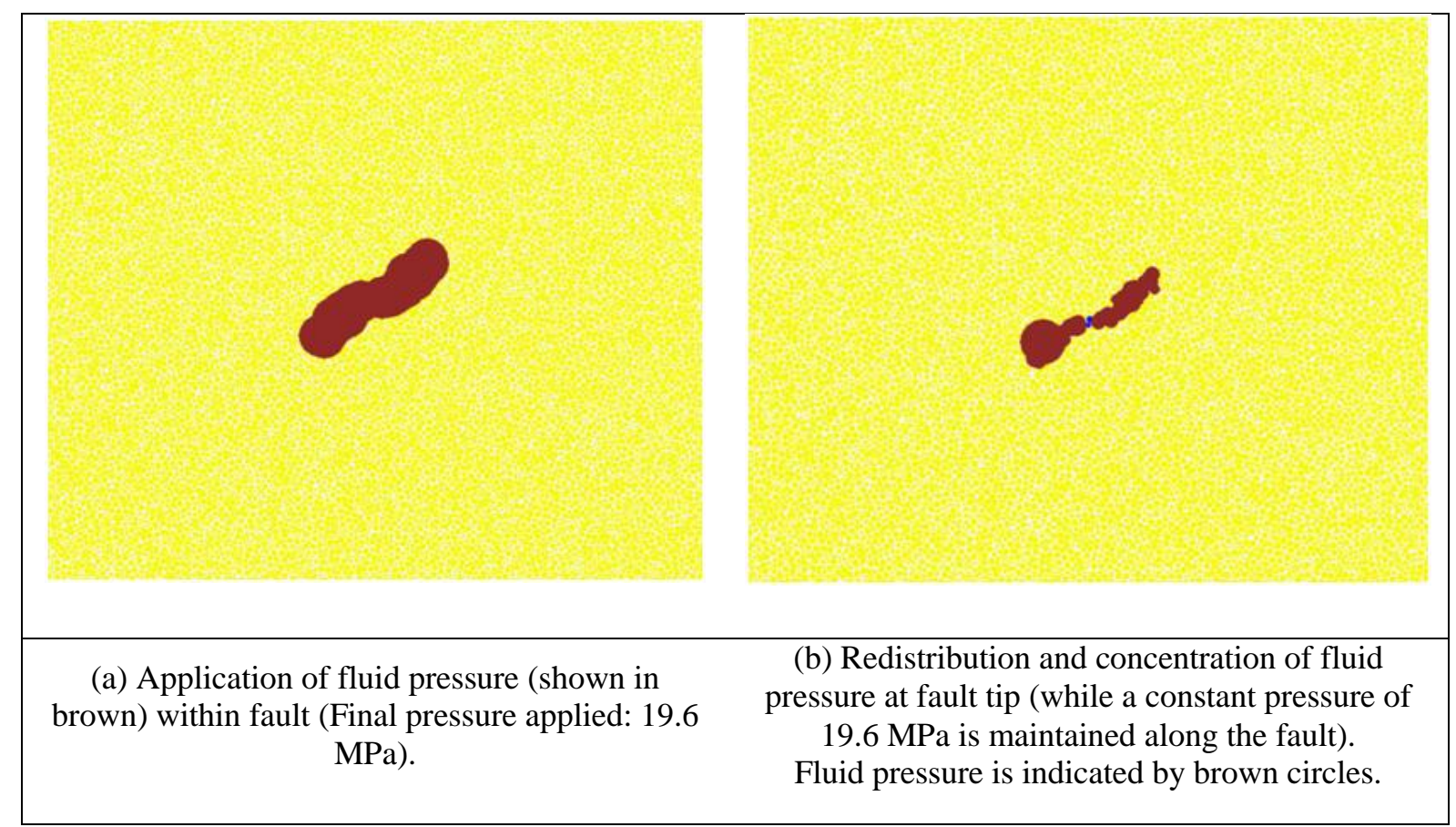



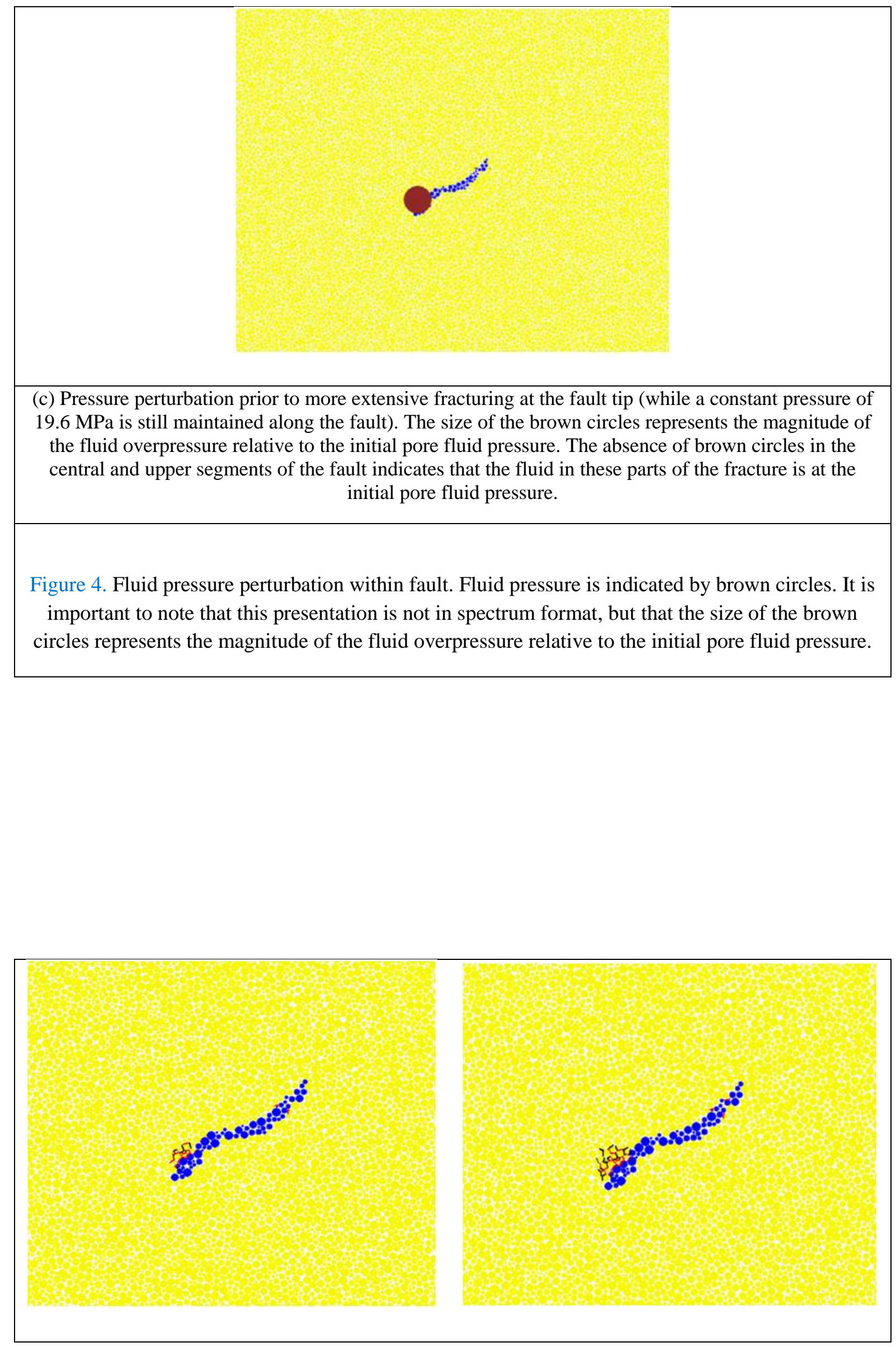


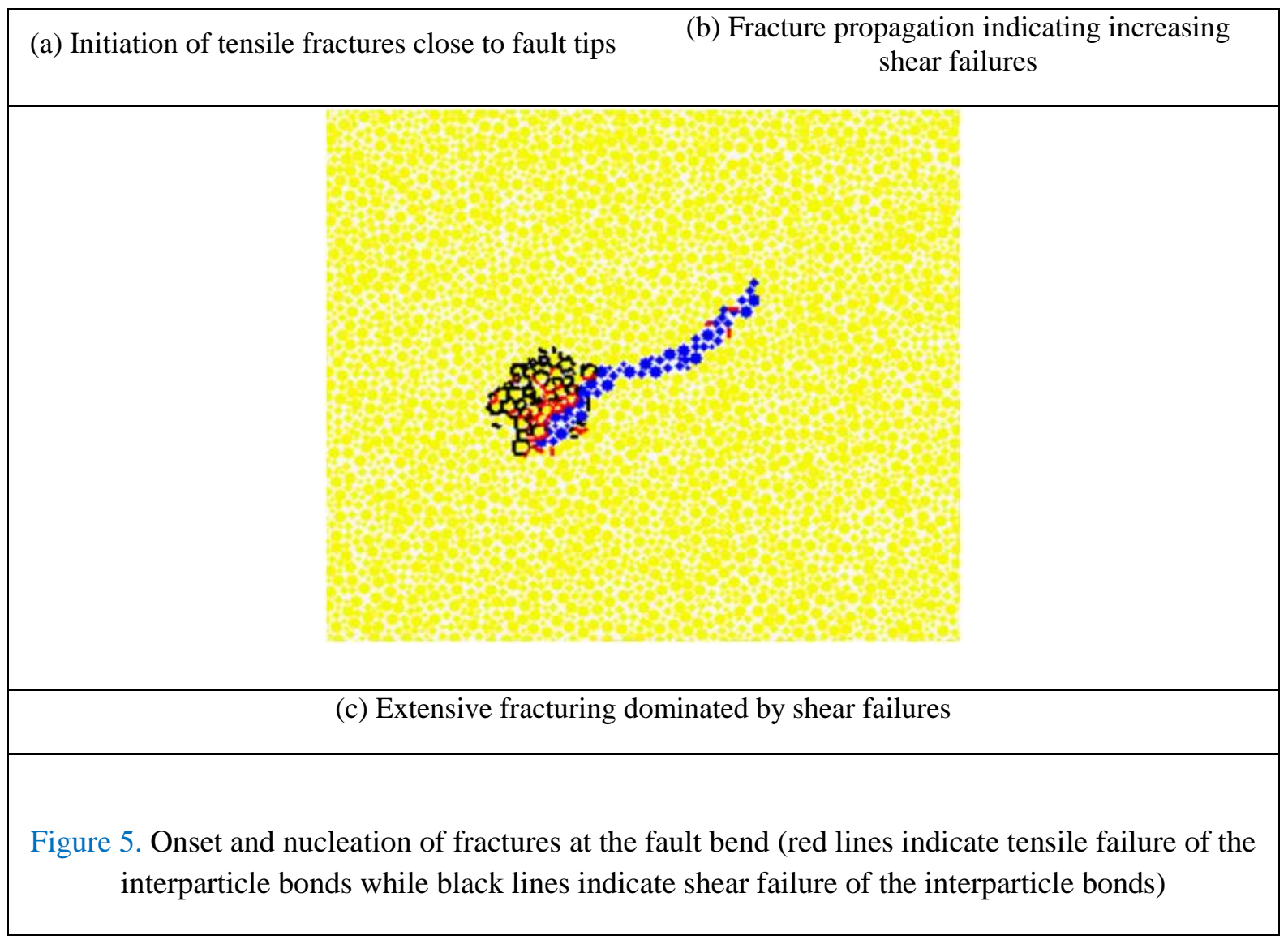

\subsubsection{Model 2: Long fault with restraining bend}

This model simulates the propagation of fractures around a restraining fault bend located within a much longer fault as a result of a pulse of high pressure fluid migrating along the fault bend. To increase the size of the stress anomaly that can develop around the fault bend, the fault was made longer so that it would accommodate more displacement. However fluid overpressure was only applied to the fault bend; the rest of the fault was normally pressured.

\subsubsection{Model description}

The model geometry comprised a c.20m long fault inclined at $45^{\circ}$ to the model boundaries, with a bend situated across the centre of the model, inclined at $78.7^{\circ}$ to the horizontal axis and $11.3^{\circ}$ to the vertical axis. The bend is $0.72 \mathrm{~m}$ long and is inclined at $33.7^{\circ}$ to the major fault. The schematic of the fault geometry is given in Figure 2 and the geometry of the actual model given in Figure 6. The initial and boundary conditions were similar to Model 1 . That is, the maximum effective horizontal stress, $\sigma_{\text {hmax }}=15 \mathrm{MPa}$, was applied in the $\mathrm{x}$ direction, while the minimum effective stress, $\sigma_{\text {hmin }}=14.4$ $\mathrm{MPa}$, was applied in the y direction, generating right lateral slip on the fault. However this fault bends towards the direction of fault slip creating a restraining bend characterised by a local compressive 
stress. Since the fault is long and was allowed to slip along its entire length, it accumulated a larger displacement than in Model 1 and consequently a greater stress anomaly around the bend.

In these models high pressure fluid is injected in a pulse along the fault plane and then allowed to seep out into the host rock pores. Fluid overpressure was applied in increasing values up to a limiting magnitude of $19.6 \mathrm{MPa}$, but only to the central section of the fault and a $1 \mathrm{~m}$ length on either side of this; the rest of the fault was normally pressured (Figure 6). Initially the fluid in the fractures is not in equilibrium with the pore fluid; it is allowed to equilibrate during the fracture propagation process. These models are thus more sophisticated than finite element models, which assume that either the fracture or pore fluids remain in equilibrium at all times (the permeable models) or that they never equilibrate (the impermeable models). The DEM models provide a means of combining the effects of dynamic fluid leak-off with the stress perturbation around fault bends, splays and tips.

\subsubsection{Model results}

Figure 7 shows the fluid pressure distribution at different periods. The higher fluid pressure at the upper section of the fault (Figure 7b-c) resulted in the initiation of fracture at this section (Figure $8 \mathrm{a}$ ). The highest magnitude of fluid pressure occurred at the upper left fault section (Figure 7c) and corresponding initial cracks occur and tend towards this direction (Figure 8a). This is in agreement with Model 1 (Releasing bend) where fluid overpressure was attained prior to the onset of fracturing.

Figure 8 indicates the onset of fractures at the upper fault section due to high perturbation of stress. The initial cracks are caused predominantly by localised tensile failure, and tend to propagate perpendicular to the fault orientation (Figure 8b). This is consistent with finite element modelling results (Welch et al., 2015; see Figure 16). The later and isolated onset of fracture at the lower fault section (Figure $8 \mathrm{~b}$ ) shows the possibility of fractures forming at other locations on the fault.

The consistent application of fluid pressure causes a build up of fluid pressure around the region of rock mass within the immediate vicinity of the fault, which tend to spread with time (Figure 9 and 10). The magnitude of fluid pressure drops significantly at these regions once encountered by the propagating fractures (Figure 9-13b). Injection of fluid in porous media often leads to an increase in the pressure at the vicinity of injection. The magnitude and trend in pressure evolution has been a subject of several studies (e.g., Zhang et al., 2013, Eshiet et al., 2012, Huang et al., 2012) and has been shown to be dependent on factors associated with the properties of the fluid, the properties of the porous material, the structural configuration of the domain and the injection flow/pressure rate. In most cases, the increase in pressure tapers off at a peak value. The time taken to reach the maximum pressure magnitude varies considerably with the prevailing operating condition. The succeeding pressure drop is attributed to leak-off of fluid/pressure due to inter-particle movements, and initiation 
of fractures and cavities. At low injection rates infiltration plays an important role as the ease of pressure dissipation and outward flow of fluid to outer zones is greater. As the injection rate is increased, infiltration is limited; pressure dissipation and outward fluid flow can only be enhanced by the creation of preferential pathways. Elevated interstitial pressures provide the driving force required for fluid migration within the rock media. The breakdown pressure coincides with the point of unstable fracture propagation and is higher than the crack initiation pressure because at the onset of crack, there is usually a further elevation in pressure before it declines (Eshiet et al., 2012, Shimizu et al., 2011, Guo et al., 1993). Sharp reductions in fluid pressure can be indicative of fluid loss and fracture propagation.

$\sigma_{\mathrm{hmin}}$
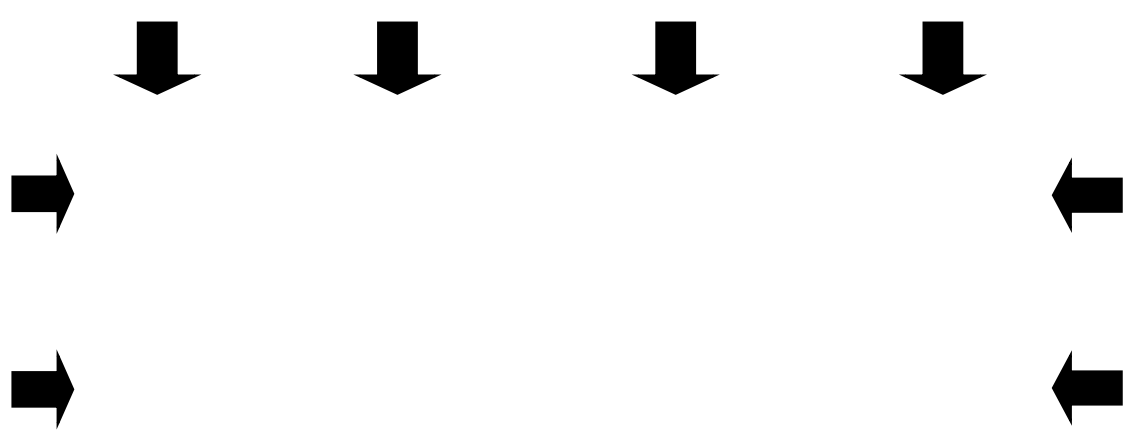

$\sigma_{\mathrm{hmax}}$

$\sigma_{\text {hmax }}$

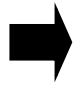




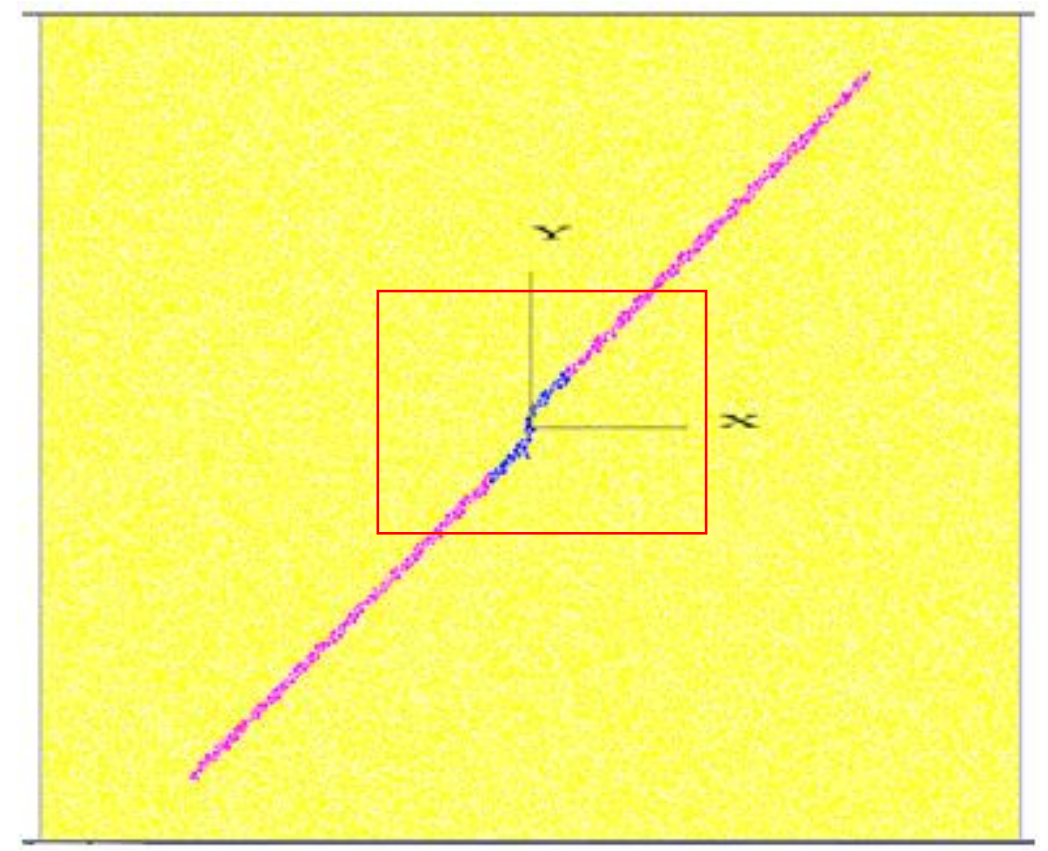

Figure 6. Geometry of pre-existing fault showing the bend at centre. Yellow circles represent the host rock, blue circles represent sections of the fault where fluid overpressure is applies, and pink circles represent sections of the fault where no fluid overpressure is applied. The red box marks the area shown in close up in Figure $7 \mathrm{c}-8$ and the $\mathrm{X}$ and $\mathrm{Y}$ line is the origin of the model/fault axis which can be used to approximate the offset of the location of crack initiation.

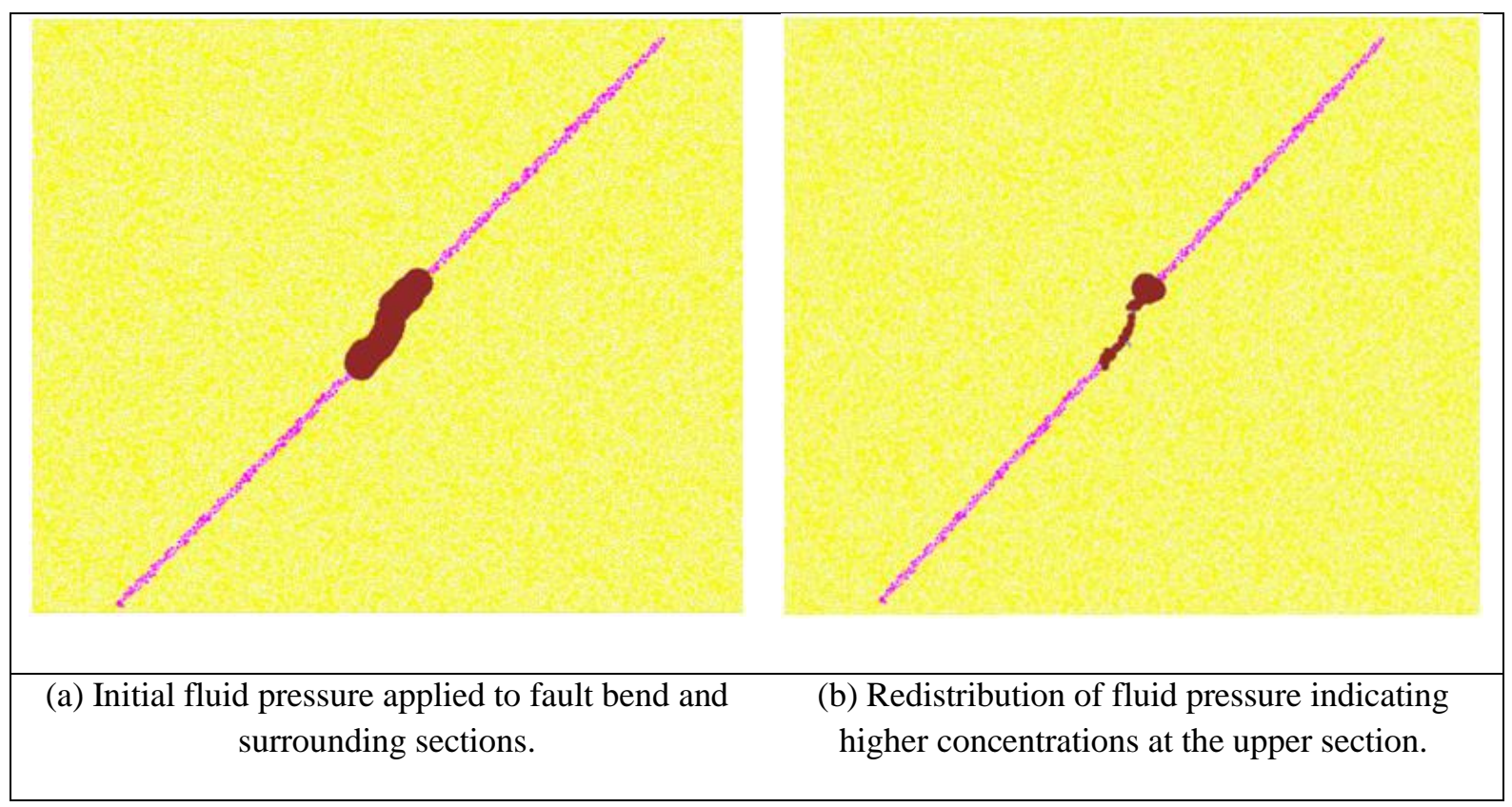




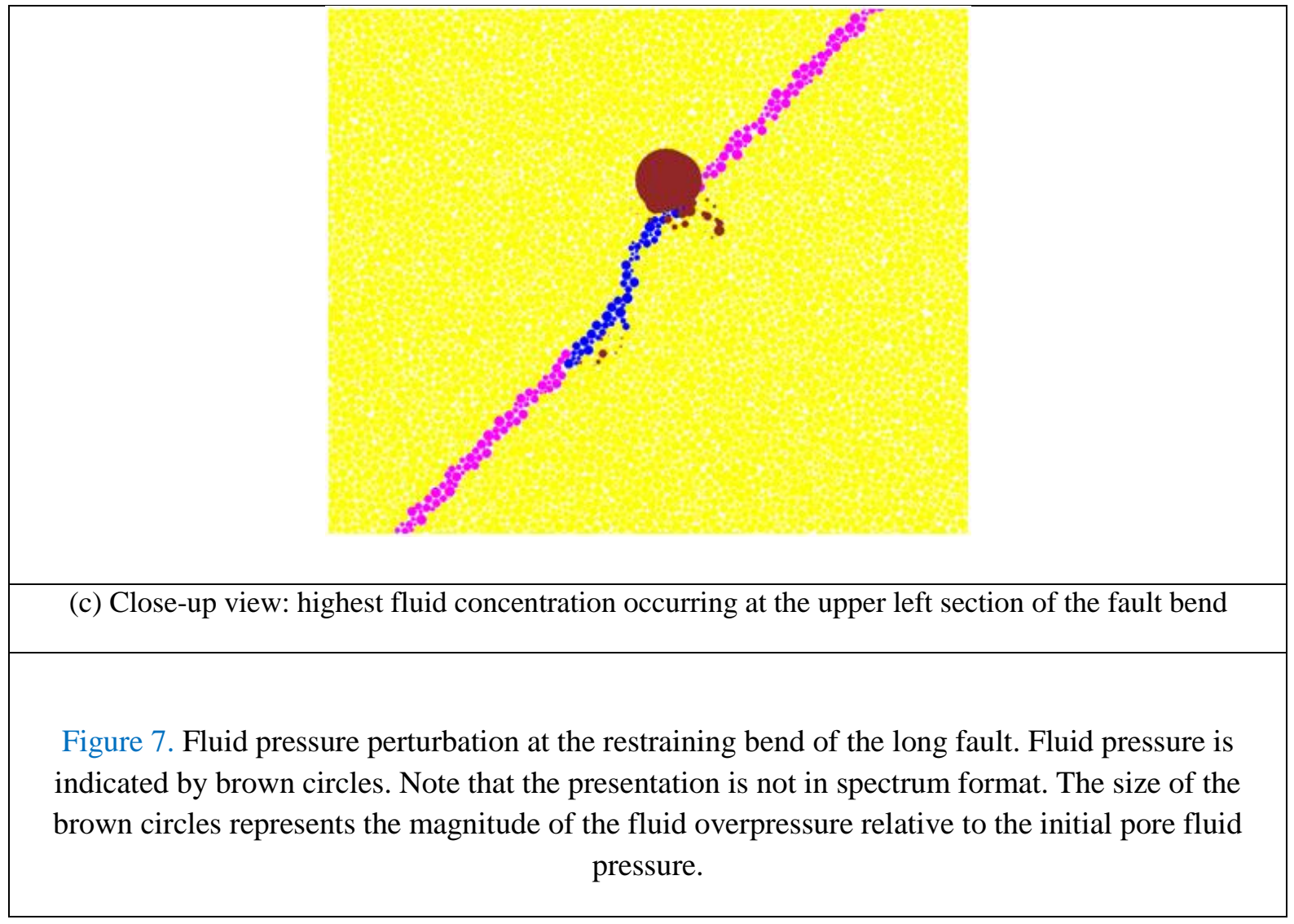

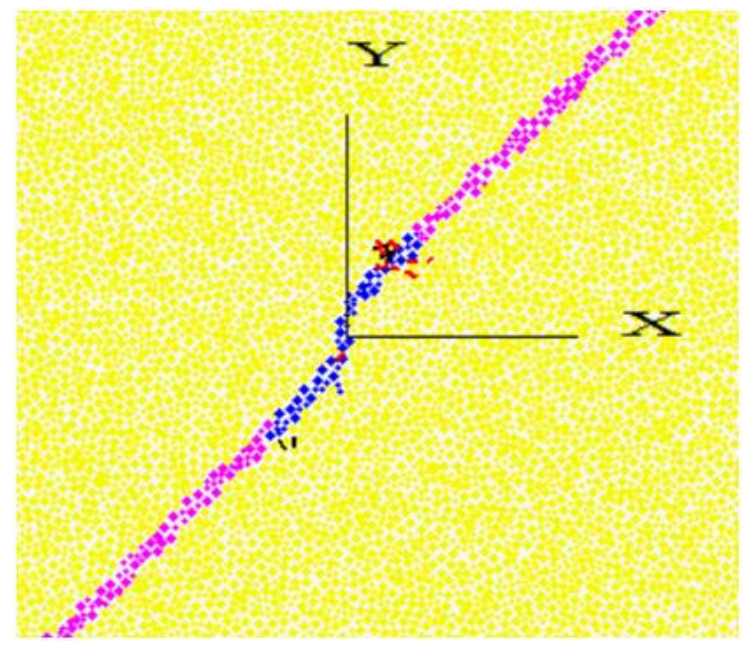

(a) Initiation of tensile fracture (red) at the upper section of the fault bend

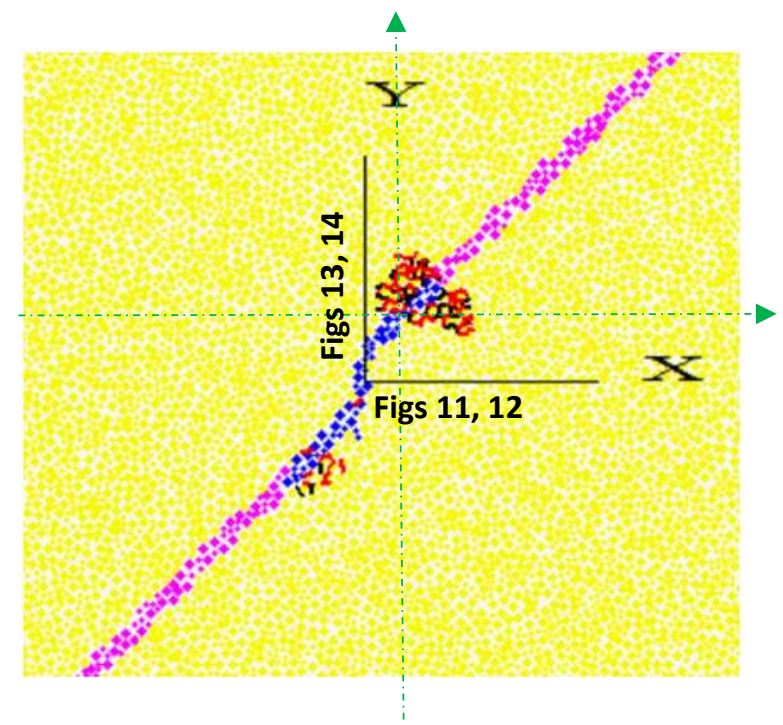

(b) Fracture propagation (Tensile: red; Shear: black) 
Figure 8. Close-up view of fracture nucleation in long fault with restraining bend

Figure 9-12 describes the fluid pressure perturbations arising during crack initiation and fracture propagation in the long fault with restraining bend (Model 2). Crack initiation occurred at a lateral distance of $0.5654 \mathrm{~m}$ in the positive $\mathrm{x}$-direction and a vertical distance of $0.8479 \mathrm{~m}$ in the positive $\mathrm{y}$ direction. Records for Figure 10 and Figure 12 were taken at offsets to the $\mathrm{x}$ and $\mathrm{y}$ axes, with the origin at the point of crack initiation (Figure $8 b$ ). The origin of axes for all plots is the centre of the model (see Figure 8). The point of crack initiation is marked by the juncture between the green horizontal and vertical lines of section, as shown in Figure 8b. This is used to indicate the offset from the centre of the model for easy reference. Pressure measurements are taken along these sections and the origin of each plot in the $\mathrm{x}$ and $\mathrm{y}$ direction is taken as the point of intersection with the main $\mathrm{y}$ and $\mathrm{x}$ axis respectively.

The pressure development herein is exemplary, typifying what would normally occur during fracture growth emanating from faults. The Cartesian coordinates of the model originates from its centre (Figure 8a) and the positions of crack initiation, crack propagation and fluid pressure distribution are described with reference to the origin of the axes. The point of crack initiation is shown as an offset from the origin of the main axes. The onset of cracking happened at a point delineated by a lateral distance of $0.5654 \mathrm{~m}$ in the positive $\mathrm{x}$-direction and a vertical distance of $0.8479 \mathrm{~m}$ in the positive $\mathrm{y}$ direction. Measurements of spatial and temporal fluid pressure distribution were taken at offsets to the $\mathrm{x}$ and $\mathrm{y}$ axes, along the dotted lines shown in Figure 10b. This is to enable direct correlations between the onset and proliferation of cracks and the corresponding evolution of fluid pressure. Fluid pressure distribution along the predesignated lines in the $\mathrm{x}$ and $\mathrm{y}$ direction is demonstrated in Figure 9-10 and Figure 11-12 respectively.

There is a build-up of interstitial fluid pressure at the vicinity of the onset of crack; however, once crack events occur fluid pressure is dissipated into adjacent areas which begin to accumulate pressure until material failure is reached. If fluid injection is stopped immediately the maximum magnitude of fluid pressure is reached, the injected fluid will infiltrate the rock through processes dependent on the rock and fluid properties. This will ultimately result in the dissipation of the fluid pressure to values less than the highest value of applied fluid pressure. In this case, the applied fluid pressure along the fault was increased in a ramp-wise manner to an upper limit of $39.2 \mathrm{MPa}$, then it was kept constant. Maintaining the fault fluid pressure at this constant value directly implies a continuous fluid flow into the rock. Where the rate of injection is greater than the leak off rate there is bound to be an increase in interstitial pressures with significantly larger values. The relationship between the fault fluid pressure and the interstitial pressure is somewhat analogous to the relationship between the fluid velocity and Darcy flux in flow through porous media. The fault fluid pressure dissipates into the surrounding rock 
as it attempts to re-establish equilibrium while forming a pressure gradient. Whereas, the fluid pressure at the span of the fault is controlled and maintained uniformly after the designated peak magnitude is attained, the interstitial pressures at the surrounds of the fault and the far reach regions are greatly influenced by the porosity of the rock. The porosity reflects the degree of compaction of the rock particles. The porosity and permeability of rocks generally decrease with compaction (e.g., Ostermeier, 2001, Hantschel and Kauerauf, 2009), for instance, when subjected to increasing confining stresses, and this effect can be four to five folds more pronounced with permeability (Ostermeier, 2001). The loss in porosity correspondingly reduces the volume occupied by the solid particles. Higher rock porosities are more likely to create steeper fluid pressure gradient. The slope of the pressure gradient becomes more gradual as porosity decreases.

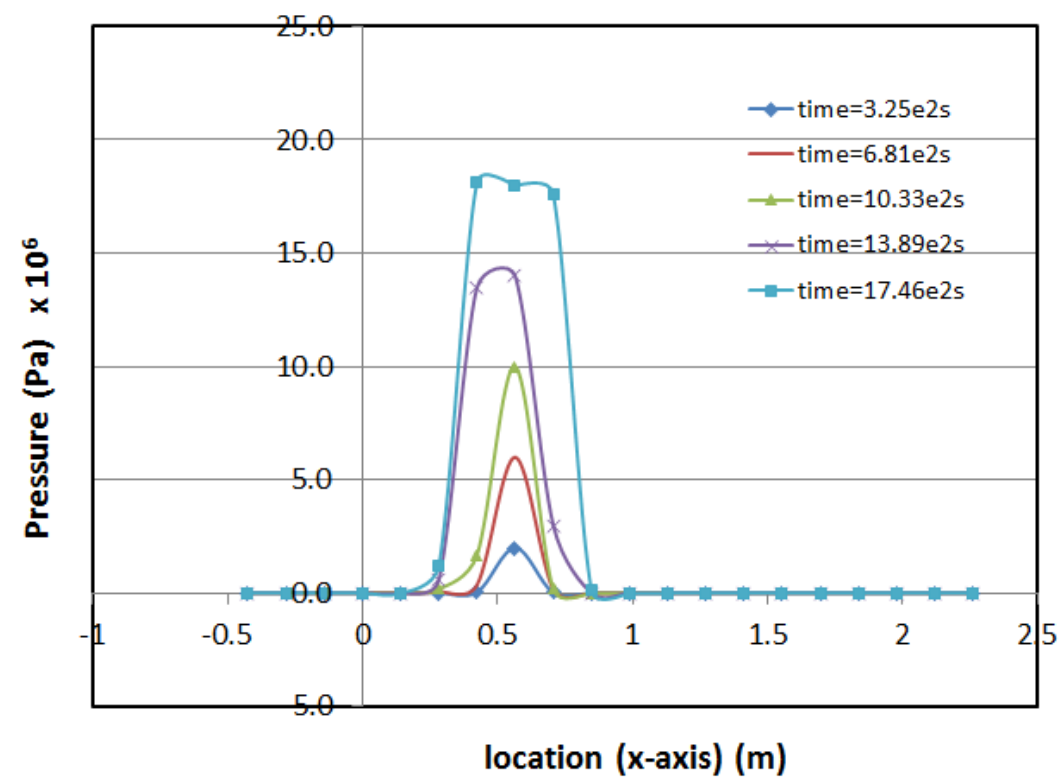

Figure 9. Pressure distribution along the $\mathrm{x}$-direction at various times (crack initiated at $0.5654 \mathrm{~m}$ ) 


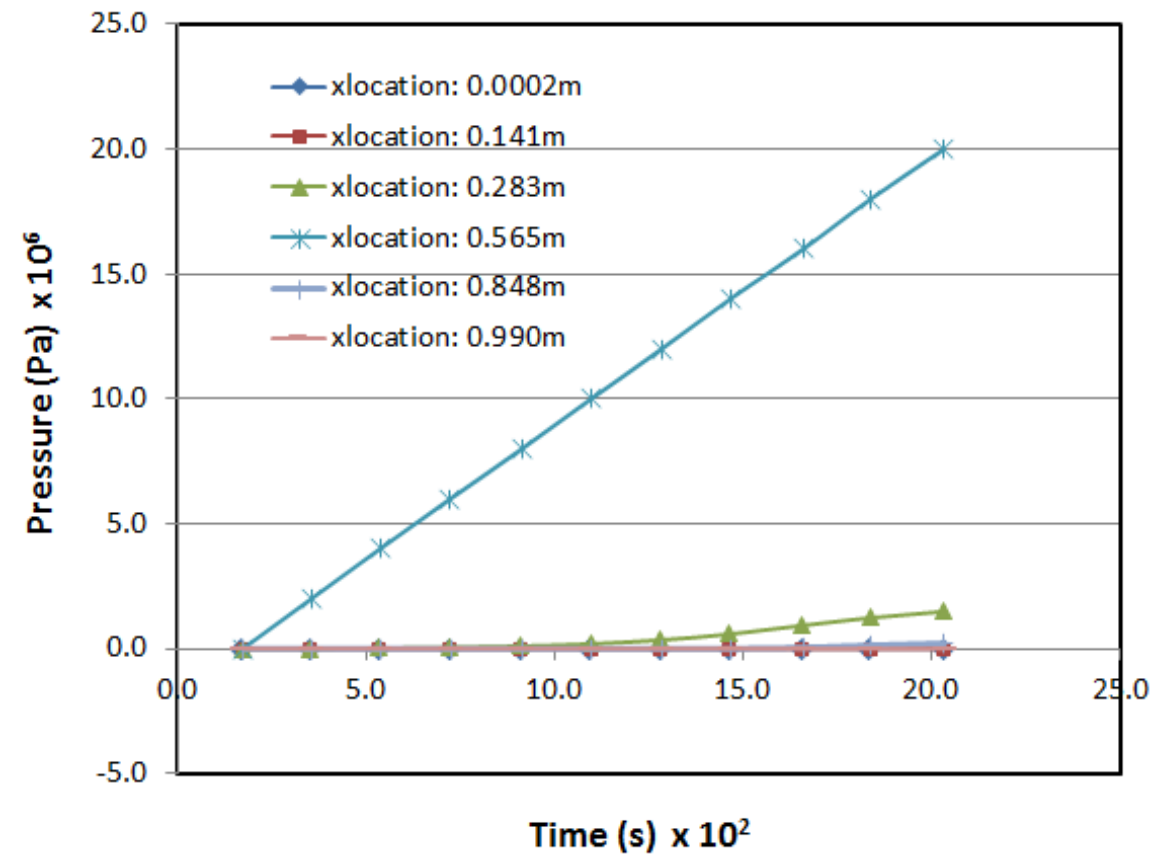

(a) Increasing pressure with time

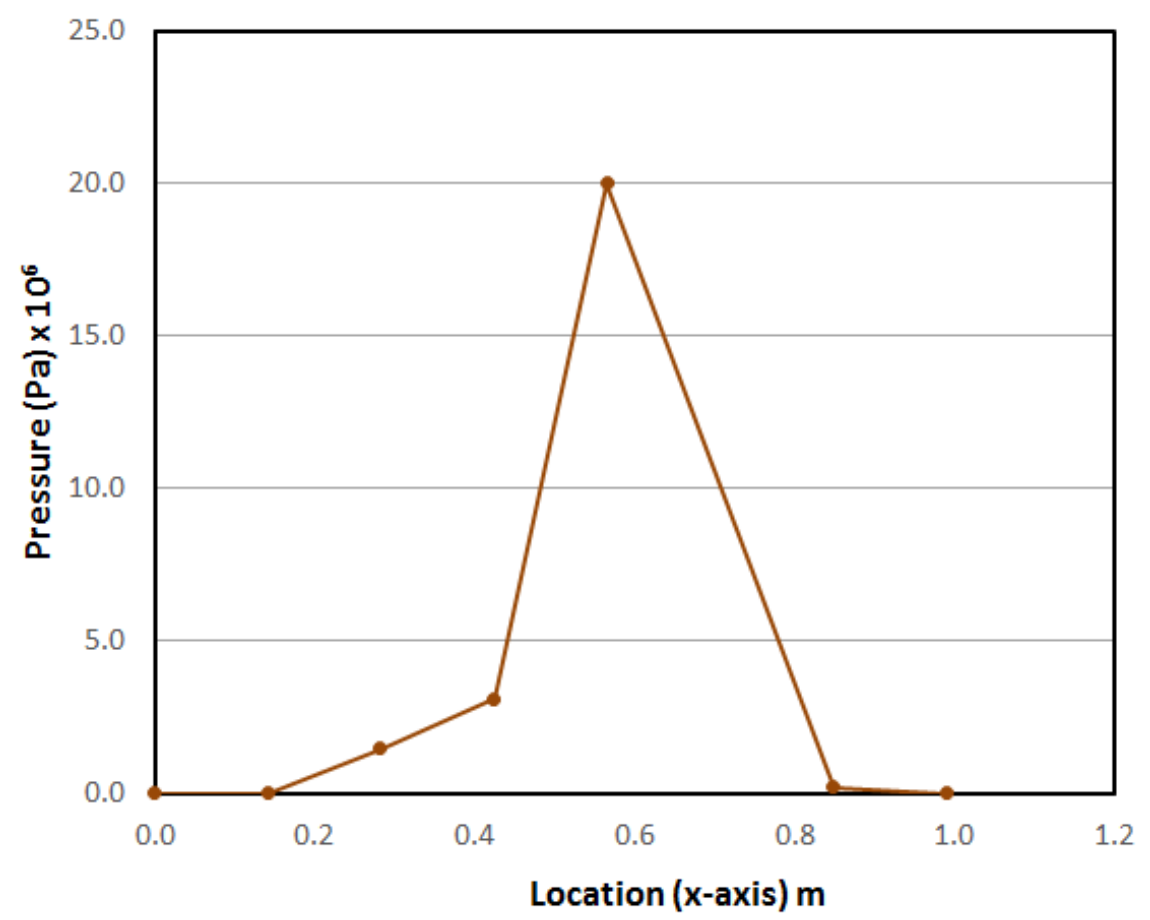

(b) Trend of fluid pressure across the fault (fault located at $0.5654 \mathrm{~m}$ )

Figure 10. Fluid pressure at different locations along the $\mathrm{x}$-direction (Referenced from the point of crack initiation) 


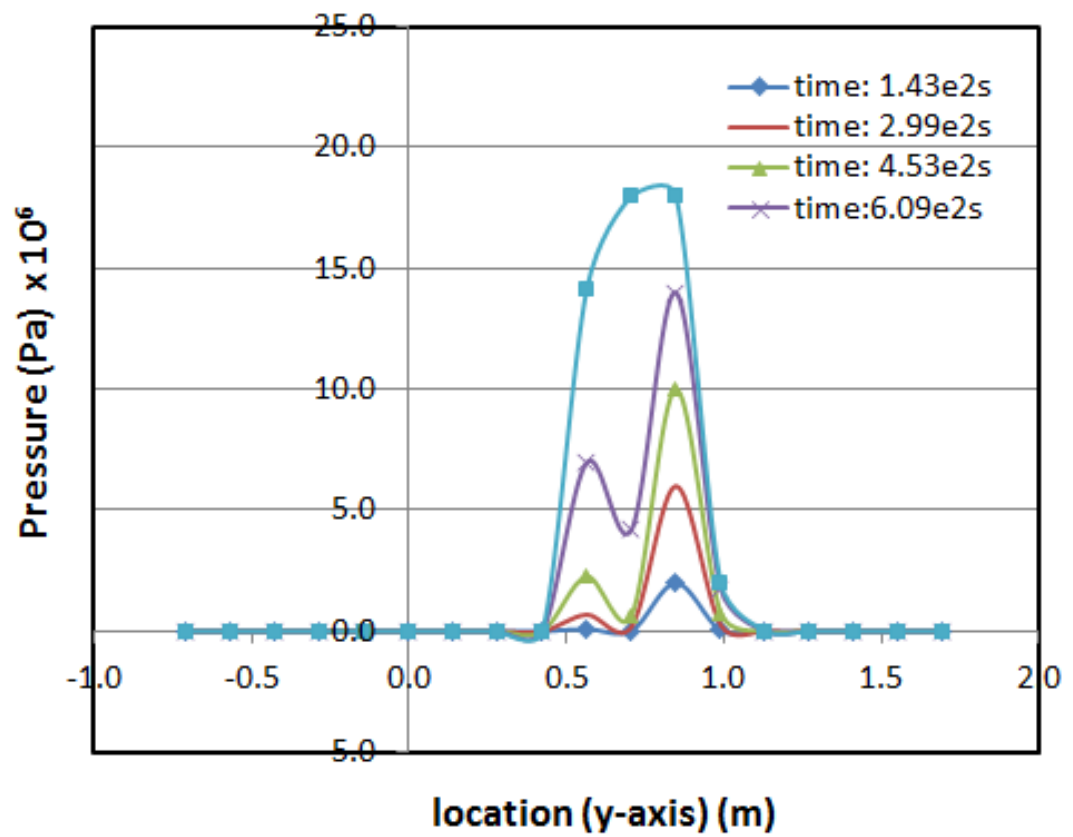

Figure 11. Fluid pressure distribution along y-direction at various times (Crack initiated at $0.8479 \mathrm{~m}$ )

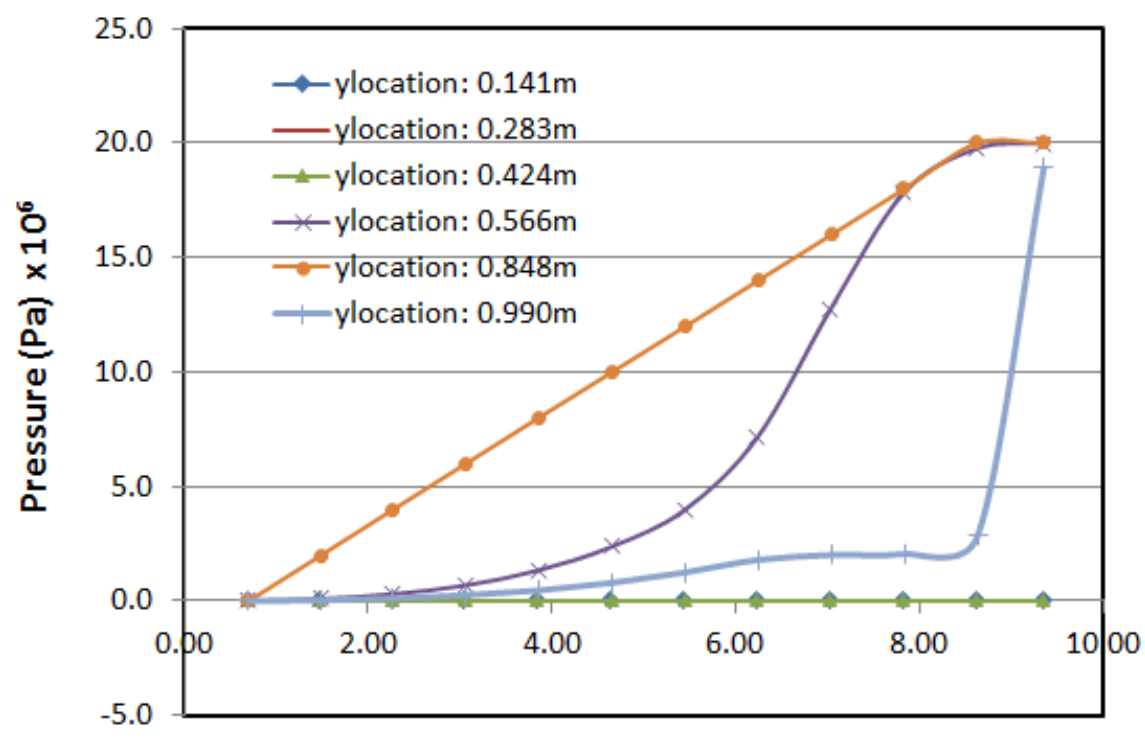

Time (s) $\times 10^{2}$

Figure 12. Increasing fluid pressure along y-direction

(Referenced from point of crack initiation) 


\subsubsection{Model 3: Long fault with restraining bend}

This model has an identical geometry to Model 2, comprising a $20 \mathrm{~m}$ long fault containing a restraining bend in the middle. However, unlike Model 2, fluid pressure is applied along the full length of the fault.

The purpose of the this model is to determine if the initiation and propagation of fracturing near the upper fault bend is caused by

- localised stress concentrations around the fault bend, or

- the dilation of the upper fault bend region that may have been caused by the fluid pressure differential between the fault bend region and the rest of the fault.

\subsubsection{Model results}

Figure 13 is a sequential representation of the fluid pressure distribution following the attainment of the maximum pressure applied at the fault. The size of the brown circles represents the magnitude of the fluid overpressure relative to the pore fluid pressure in surrounding areas. Crack initiation and propagation is demonstrated in Figure 14a and Figure 14b respectively, while the contact force distribution corresponding to the fracturing pattern in Figure 14b is shown in Figure 15b.

Figure 13a shows the fluid overpressure applied along the entire stretch of fault. The same magnitude of fluid pressure (19.6 MPa) was applied along the whole fault stretch. The pictorial representations of fluid pressure depicted in Figure 13a and Figure 13b are relative, showing the disparity in fluid pressure perturbations associated with the fault architecture. Higher pore fluid pressures do not occur exactly on the fault line but in surrounding zones. Areas close to the bend are prone to higher pressure build-up. As a result, fractures are more likely to start and prevail around these zones. This is further emphasised in Figure 13b. However, in Figure 13c pockets of relatively high fluid pressure occur at selected locations, which also include the upper corner of the fault bend, further highlighted in Figure 15 f Figure 13d, where it becomes apparent that the upper fault bend corner is subjected to the highest magnitude of fluid pressure.

Figure 14 shows that the initial fracturing occurs in the vicinity of the fault bend, which is evidence of the greater stress magnitudes that develop here. The contact force distribution shown in these figures indicates considerably higher magnitudes of tensile forces at the proximity of the fault bend. This is similar to the results obtained from Finite Element models of fracture propagation around a restraining bend in both permeable and impermeable rocks under overpressured conditions (Welch et al., 2015; see Figure 16). However as fluid pressure increases, fracturing occurs in the host rock immediately adjacent to the main fault, rather than propagating away from the fault (Figure 14b and 
15a). This will generate localised fracture patterns around the faults rather than fracture corridors observed in the finite element models. This may be due to the fluid leak-off in these models limiting the fluid pressure that can build up in the faults, and suggests that for fracture corridors to form the high pressure fluid pulses must either be very rapid or the host rock must be impermeable.

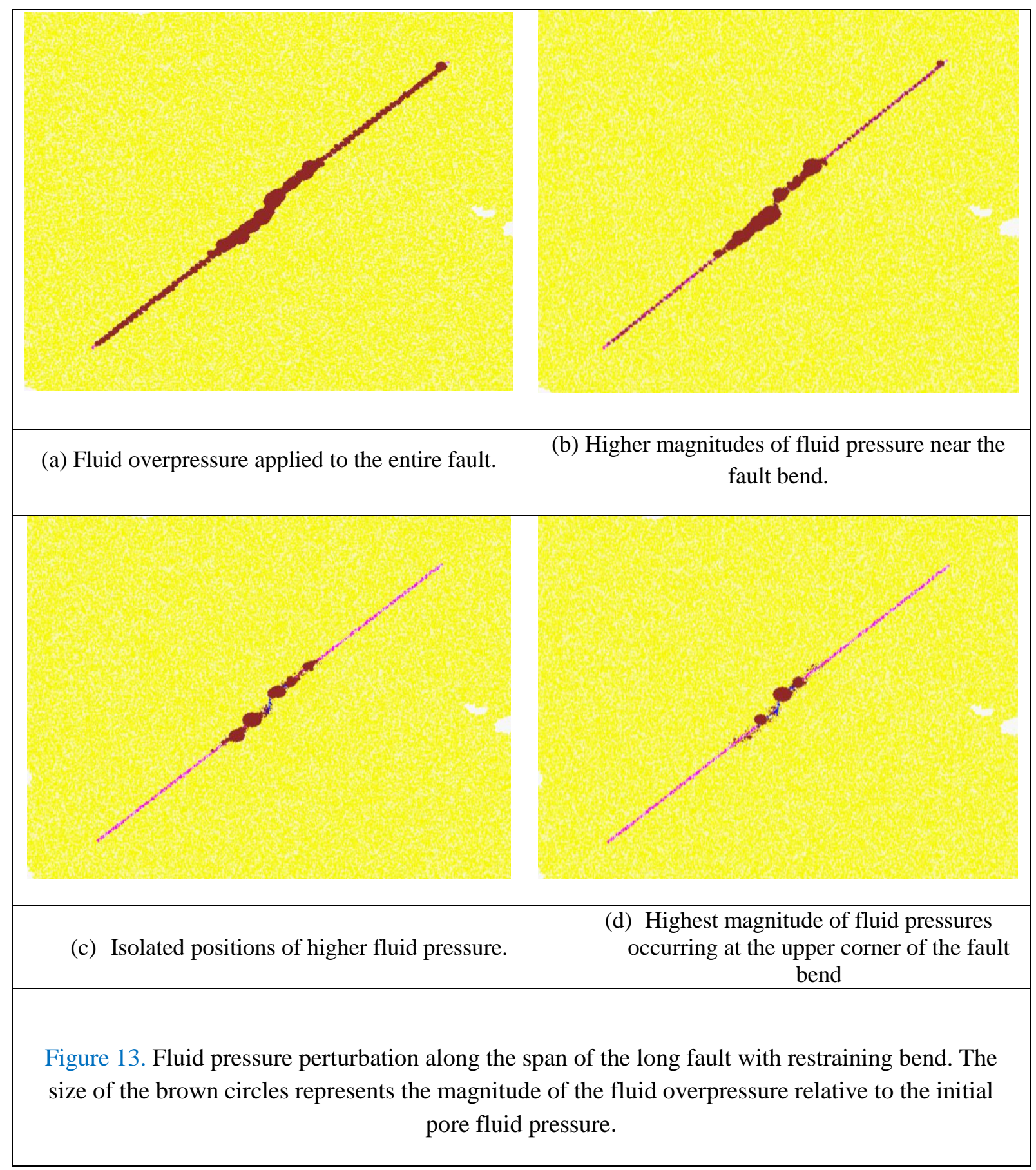




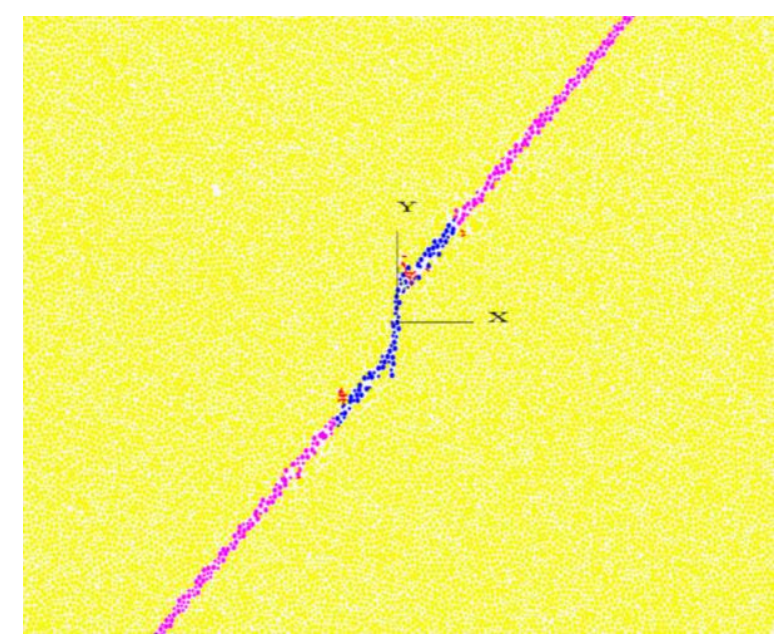

(a) Fracture initiation at the upper corner of the fault bend.

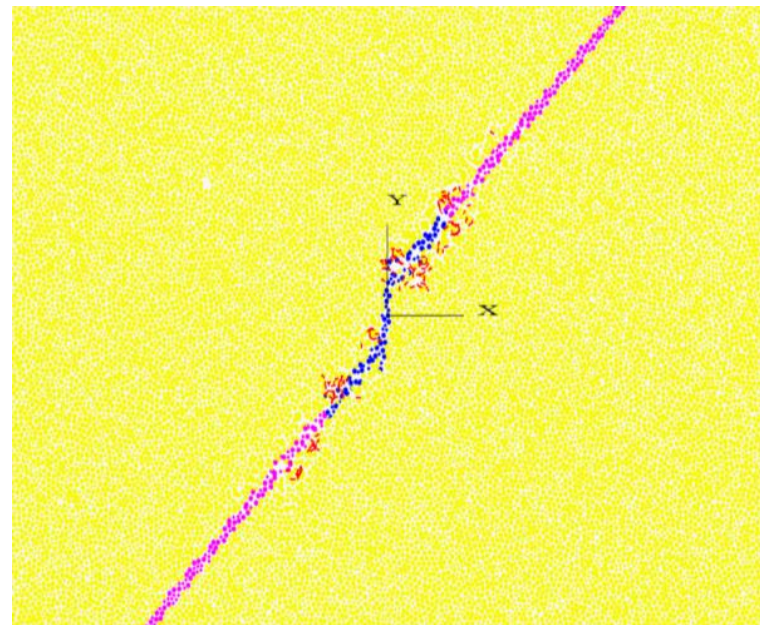

(b) ) Progression of fracturing events around the fault bend.

Figure 14. Fracture nucleation along the span of the long fault with restraining bend. Red lines indicate tensile failure of the interparticle bonds while black lines indicate shear failure of the interparticle bonds. The blue section of the fault correspond with the dimensions of the overpressured zone in Model 2. This has been made so for easy comparison between the models, but does not reflect any variation in properties or applied overpressure in this model.

As observed earlier, pockets of high fluid pressure occurred at several locations at and around the fault bend (Figure 13b and Figure 13c), with a high tendency for fractures to be initiated at any of such locations. Also, the contact force distribution shows significantly greater magnitudes of tensile forces within the vicinity of the fault bend (Figure 15). For this particular instance, the highest stress concentration occurred at the upper corner of the fault bend making it only normal for the onset of fracturing to happen there. The fact that the highest stress concentrations occur around the fault bend due to its presence is an interesting observation and highlights the propensity for fracturing to take place within this region. Comparisons have been made to FEM results illustrated in Welch et al. (2015) shown in Figure 16. The warm colours indicate areas of high fluid pressure and likely fracture initiation.

Although the model and fault configuration is built to be symmetrical about the centre, this is not strictly so mainly because of disparities arising from the irregularity in particle sizes and its distribution. The range of particle size and the randomness of the particle assembly may affect the symmetry. This can be mitigated by using finer particles and/or decreasing the range of particle size. However, in reality, rocks are constituted by grains with a wide range of sizes. 


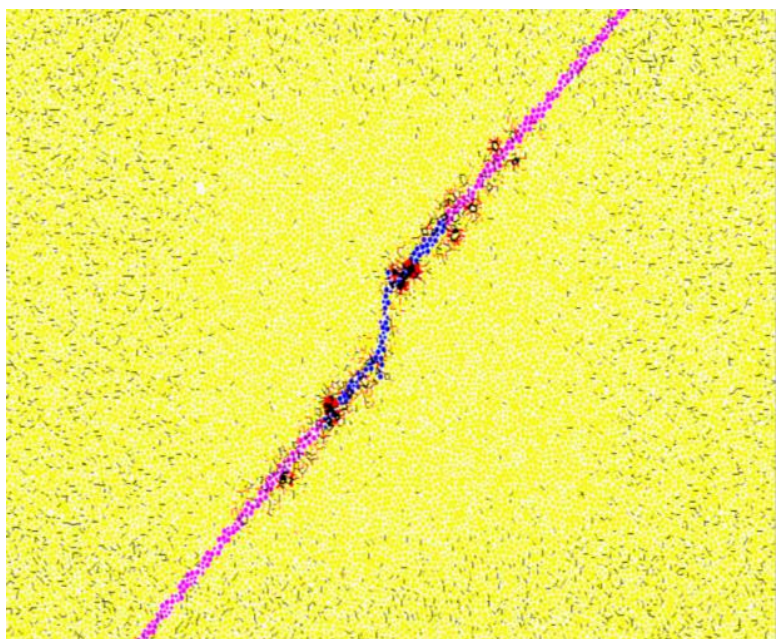

(a) Contact force distribution during fracture initiation.

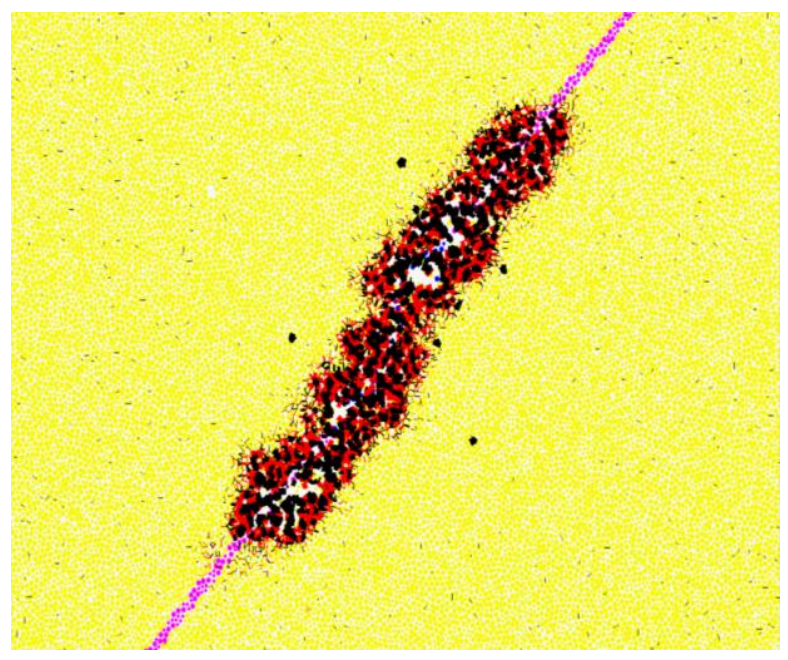

(b) Contact force distribution at later stages.

Figure 15. Contact force evolution in the domain of the long fault with restraining bend. Red colours indicate tensile forces while black colours indicate shear forces.

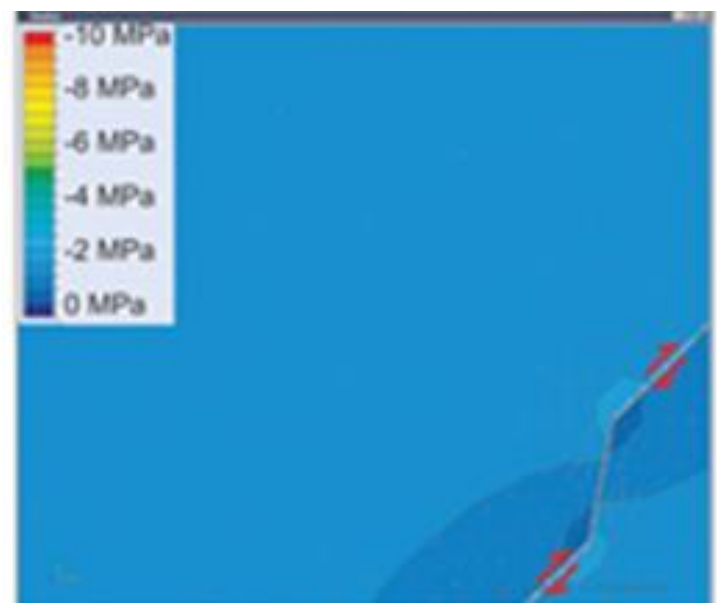

a) Step 1: No fracture

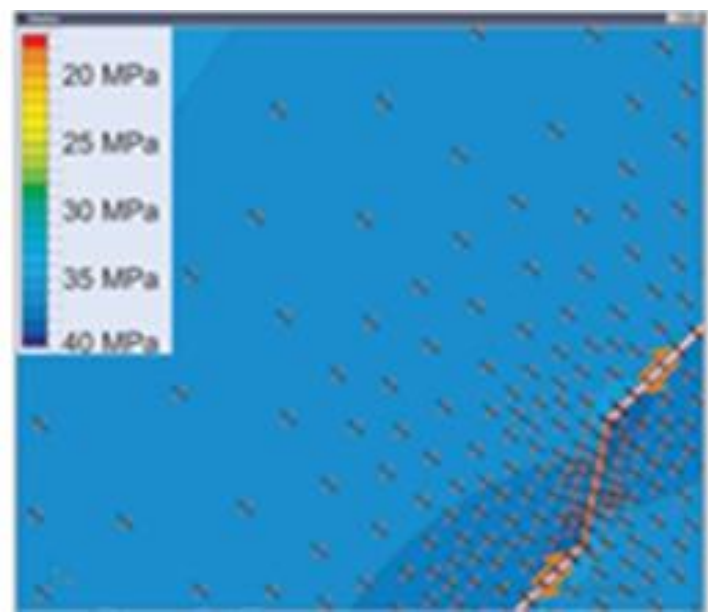

c) Step 1: No fracture 


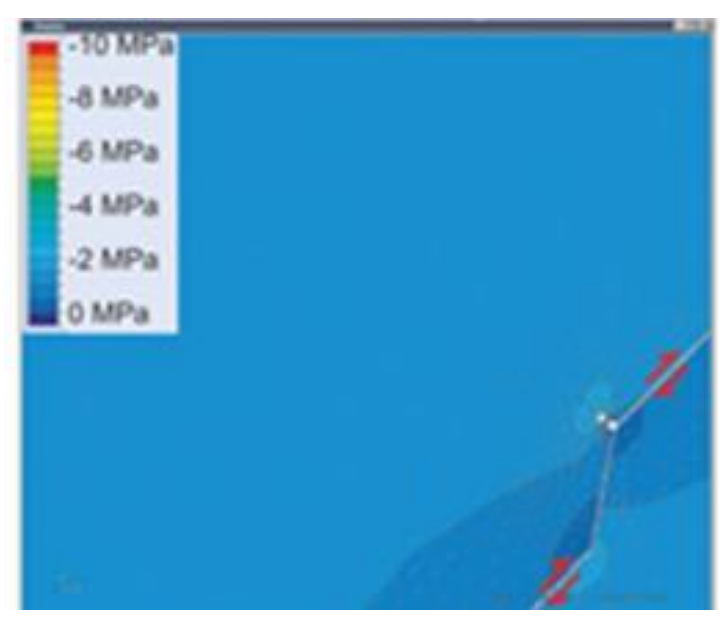

b) Step 2: fracture length $0.1 \mathrm{~m}$

\section{Fracture initiation of permeable rock}

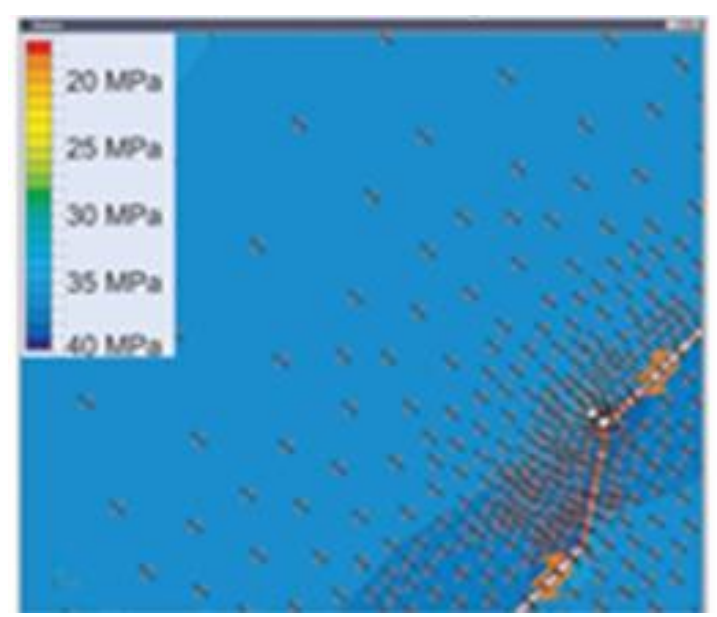

d) Step 2: fracture length $0.1 \mathrm{~m}$

Fracture initiation on impermeable rock

Figure 16. Fracturing on strike slip faults with a restraining bend (Welch et al., 2015)

\subsection{Summary and Conclusions}

The influence of pre-existing naturally occurring faults on fracture behaviour has been assessed using DEM models. The purpose of the study was mainly to highlight controls impacting on fracture initiation and propagation at the vicinity of faults with respect to: the point of fracture onset, fracture orientation and fracture intensity. In terms of orientation, the two types of faults investigated include: a strike-slip fault consisting of a releasing bend and a strike slip fault consisting of a restraining bend. Based on the fault type and application of fluid pressure three cases were considered. The first case implied fluid overpressure at the releasing bend of a short fault. For the second case the same condition of fluid overpressure was applied to the restraining bend of a longer fault, although fluid overpressure was only applied to a short segment of the fault around the bend. A third case was included where fluid overpressure was applied on the entire span of a long fault with a restraining bend. For all cases, although fluid pressure was applied incrementally, the condition of maximum fluid overpressure had to be attained before onset of fracture. At the fault with the releasing bend, stress perturbation around the bend resulted in fluctuations and a redistribution of fluid pressure, with the highest fluid pressure occurring at the lower edge (tip) of the bend. Consequently, the initiation of tensile fractures occurred at this position due to tensile failure, with shear fractures becoming dominant during the outward fracture propagation. Also, the general orientation of propagating fractures tends to be perpendicular to the fault plane. 
The DEM modelling exhibits some advantages over traditional FEM models, such as dynamic representations of nucleation and propagation of fracturing events, the non-requirement of preembedded fractures (as in FEM) since cracks are not artificially place but occur explicitly due to bond breakages and particle separation, graphical illustration of fluid pressure perturbation, a natural depiction of all fluid induced fractures from the position of crack initiation to the direction of fracture propagation, a demonstration of the possibility of later-stage fracturing at other sections away from the fault bend/tips and a micro-scale evaluation of the geomechanical phenomenon. Furthermore, unlike the finite element models in Welch et al. (2015), which assume that either the fracture or pore fluid remain in equilibrium (for permeable models) or never reach equilibrium (for impermeable models), the DEM model has been fully coupled with fluid flow to directly simulate the concentration and propagation of fluid pressure within the porous rock and the fracturing events they eventually induce. They can therefore more accurately model deformation due to high pressure fluids injected into permeable rocks along faults.

For the fault with the restraining bend, stress perturbation resulted in greater a concentration of fluid pressure at the upper section of the bend near the edge (tip), leading to a high tendency of fracture initiation at this region. The direction of fracture propagation was generally perpendicular to the inclination of the restraining bend, and initiation and propagation of fractures was dominated by tensile and shear failure, respectively. This is similar to the orientation of fractures observed at the releasing bend. Therefore, rapid fracture propagation is mainly driven by the stress field around fault bends as well as the fluid pressure, with stress perturbations causing higher magnitudes of fluid pressure at the edges of fault bends.

The results obtained above are comparable to the FEM results presented in Welch et al. (2015), in terms of the pattern of fracture propagation originating from a releasing/restraining bend in a frictionless fault subjected to fluid overpressure. The orientation of fractures and direction of propagation are especially observed as similar. Also in agreement is the location of fracture initiation which occurred close to the lower and upper end of the fault bend, for case 1 and case 2, respectively. Further confirmation of these results was made by a third case study (case 3), whereby fluid overpressure was applied to the entire fault.

However the DEM models do not reproduce the fracture corridors seen in the FEM models, but instead we see deformation developing all around the fault, forming a damage zone. This suggests that in permeable rock, where fluid leak-off is significant, we are more likely to form damage zones localised around the faults rather than fracture corridors propagating away from the faults. 


\section{Nomenclature}

$a$

$a_{o} \quad$ Residual aperture $(m)$

A Cross-sectional area of model sample $\left(\mathrm{m}^{2}\right)$

$\beta \quad$ a multiplier factor

DEM Discrete Element Method

$D_{p} \quad$ Depth of perforation channel $(m)$

$D_{w} \quad$ Well diameter $(m)$

E $\quad$ Elastic modulus $(P a)$

F $\quad$ Compressive force $(N)$

$F_{o} \quad$ Compressive force at which the residual aperture reduces to half $(N)$

$g$

$h$

$H \quad$ Height of model sample $(m)$

$k \quad$ Intrinsic permeability $\left(\mathrm{m}^{2}\right)$

$K_{f} \quad$ Bulk modulus of fluid $(\mathrm{Pa})$

$L \quad$ Length of model sample $(m)$

$L_{p} \quad$ Channel (pipe) length $(m)$

m Multiplier factor

$\triangle P \quad$ Pressure gradient $(P a)$

$\rho_{f} \quad$ Fluid density $\left(\mathrm{Kg} / \mathrm{m}^{3}\right)$

$\rho_{s} \quad$ Particle (dry) density 
Sum of flow rates $\left(\mathrm{m}^{3} / \mathrm{s}\right)$

$Q_{i} \quad$ Flow rate at inlet of sample $\left(\mathrm{m}^{3} / \mathrm{s}\right)$

$Q_{o} \quad$ Flow rate at outlet of sample $\left(\mathrm{m}^{3} / \mathrm{s}\right)$

$Q_{p} \quad$ Flow rate for each pipe between domains (Discharge rate) $\left(\mathrm{m}^{3} / \mathrm{s}\right)$

$Q_{s} \quad$ Steady state flow rate $\left(\mathrm{m}^{3} / \mathrm{s}\right)$

$R_{l o} \quad$ Minimum particle radius $(m)$

$R_{\text {ratio }} \quad$ Particle size ratio

$r_{1}, r_{2} \quad$ Radius of a given pair of particles in contact $(m)$

$S \quad$ Saturation

$\Delta t \quad$ Timestep $(s)$

$V \quad$ Volume of model sample $\left(\mathrm{m}^{3}\right)$

$V_{d} \quad$ Apparent volume of the domain $\left(\mathrm{m}^{3}\right)$

$V_{p} \quad$ Volume of flow pipe $\left(m^{3}\right)$

$v \quad$ Poisson's ratio

$w \quad$ Channel width $(m)$

$\mu \quad$ Fluid viscosity $\left(\mathrm{Pa}-\mathrm{S}\right.$ or $\left.\mathrm{N} \cdot \mathrm{s} / \mathrm{m}^{2}\right)$

$\phi \quad$ Porosity

$\sigma_{c} \quad$ Compressive strength $(\mathrm{Pa})$

$P_{p} \quad$ Pore fluid pressure (hydrostatic)

$P_{f} \quad$ Final fracture fluid pressure

$\sigma_{v} \quad$ Total lithostatic stress

$\sigma_{v} \quad$ Effective lithostatic stress

$\sigma_{\text {hmax }} \quad$ Maximum horizontal stress $(\mathrm{Pa})$ 
$\sigma_{\text {hmin }} \quad$ Minimum horizontal stress $(\mathrm{Pa})$

\section{References}

Abe, S., Van Gent, H. \& Urai, J. L. 2011. DEM simulation of normal faults in cohesive materials. Tectonophysics 512, 12-21.

Al-Busaidi, A., Hazzard, J. F. \& Young, R. P. 2005. Distinct element modeling of hydraulically fractured Lac du Bonnet granite. Journal of Geophysical Research, 110, B06302, doi:10.1029/2004JB003297.

Alonso-Marroquin, F. 2008. Spheropolygons: A new method to simulate conservative and dissipative interactions between 2d complex-shaped rigid bodies. Europhysics Letters, 83 (1) (2008) 14001 .

Ameen, M. S. 1995a. Fracture characterization in the Chalk and the evolution of the Thanet monocline, Kent, southern England. Geological Society, London, Special Publications, 92 (1), $149-174$. 
Andre, D., Jebahi, M., Iordanoff, I., Charles, J.-I. \& Neauport, J. 2013. Using the discrete element method to simulate brittle fracture in the indentation of a silica glass with a blunt indenter. Comput. Methods Appl. Mech. Engrg., 265, 136-147.

Athavale, A. S. \& Miskimins, J. L. 2008. Laboratory hydraulic fracturing on small homogeneous and laminated blocks. 42nd US Rock Mechanics Symposium, San Francisco June 29-July 2, 2008.

Bai, Q.-S., Tu, S.-H. \& Zhang, C. 2016. DEM investigation of the fracture mechanism of rock disc containing hole(s) and its influence on tensile strength. Theoretical and Applied Fracture Mechanics, 86, 197-216.

Bear, J. 1979. Hydraulics of Groundwater. McGraw-Hill, New York.

Blair, S. C., Thorpe, R. K., Heuze, F. E. \& Shaffer, R. J. 1989. Laboratory observations of the effect of geologic discontinuities on hydrofracture propagation. Rock Mechanics as a Guide for Efficient Utilization of Natural Resources, Khair (ed.), Balkema, Rotterdam.

Bourne, S. J. \& Willemse, E. J. M. 2001. Elastic stress control on the pattern of tensile fracturing around a small fault network at Nash Point, UK. Journal of Structural Geology, 23 (11), 1753-1770.

Casas, L., Miskimins, J. L., Black, A. \& Green, S. 2006. Laboratory hydraulic fracturing test on a rock with artificial discontinuities. SPE Annual Technical Conference and Exhibition, San Antonio, Texas, USA 24-27 September 2006

Chen, Z., Jeffrey, R. G., Zhang, X. \& Kear, J. 2016. Finite-element simulation of hydraulic fracture interacting with a natural fracture. SPE Journal, 22 (1), 219-234.

Chi, E., Zhao, M., Lui, J. \& Kang, Q. 2015. Numerical modeling of rock fracture and fragmentation under impact loading using discrete element method. Advance in Mechanical Engineering, 7 (6), 1-5.

Cho, N., Martin, C. N. \& Sego, D. C. 2007. A clumped particle model for rock. International Journal of Rock Mechanics and Mining Sciences, 44, 997-1010.

Chuprakov, D., Melchaeva, O. \& Prioul, R. 2013. Hydraulic fracture propagation across a weak discontinuity controlled by fluid injection. . In: Bunger, A., McLennan, J. \& Jeffrey, R. (eds.) Effective and Sustainable Hydraulic Fracturing. Croatia: Intech.

Chuprakov, D. A., Akulich, A. V., Siebrits, E. \& Thiercelin, M. 2010. Hydraulic fracture propagation in a naturally fractured reservoir. SPE Oil and Gas India Conference and Exhibition in Mumbai, India, 20-22 January 2010.

Cundall, P. 2000. Fluid Formulation for PFC2D. Itasca Consulting Group: Minneapolis, MN, USA.

Daneshy, A. A. 1978. Hydraulic fracture propagation in layered formations. Spe Journal, 18, 33-41.

Dehghan, A. N., Goshtasbi, K., Ahangari, K., Jin, Y. \& Bahmani, A. 2017. 3D numerical modeling of the propagation of hydraulic fracture at its intersection with natural (pre-existing) fracture. Rock Mech Rock Eng. , 50 (2), 367-386.

Dullien, F. a. L. 1992. Porous media - fluid transport and pore structure. Academic Press, Inc, San Diego. 
Escobar, R. G., Sanchez, E. C. M., Roehl, D. M. \& Romanel, C. 2016. Numerical modeling of fracture containment in multi-layered formations using a cohesive zone model. VII Brazilian Symposium on Rock Mechanics - SBMR 2016, Rock Mechanics and Rock Engineering for Innovation and Development ISRM Specialized Conference 19-22 October. Belo Horizonte, Minas Gerais, Brazil

Eshiet, K. I.-I. \& Sheng, Y. 2016. The role of rock joint frictional strength in the containment of fracture propagation. Acta Geotecnica, DOI: 10.1007/s11440-016-0512-2.

Eshiet, K. I.-I., Sheng, Y. \& Ye, J. 2012. Microscopic modelling of the hydraulic fracturing process. Environmental Earth Sciences, 68: 4, 1169-1186.

Eshiet, K. I. \& Sheng, Y. 2011. Investigation of geomechanical responses of reservoirs induced by carbon dioxide storage. SPE Canadian Unconventional Resources Conference. Alberta, Canada.

Eshiet, K. I. \& Sheng, Y. 2015. Inter-relationship between joint dilatancy and frictional resistance: impact on fracture behaviour. IOP Conf. Series: Earth and Environmental Science, 26 (2015) 012053 .

Fakhimi, A. \& Wan, F. 2016. Discrete element modeling of the process zone shape in mode I fracture at peak load and in post-peak regime. International Journal of Rock Mechanics \& Mining Sciences 85 (2016) 119-128.

Galindo-Torres, S., Alonso-Marroquin, F., Wang, Y. C., Pedroso, D. \& Munoz Castano, J. 2009. Molecular dynamics simulation of complex particles in three dimensions and the study of friction due to nonconvexity. Physical review. E, Statistical, nonlinear, and soft matter physics, 79 (6) 060301.

Galindo-Torres, S. \& Pedroso, D. 2010. Molecular dynamics simulations of complex-shaped particles using Voronoi-based spheropolyhedra. Physical Review. E. Statistical Nonlinear and Soft Matter Physics, 81 (6 Pt 1) 061303.

Galindo-Torres, S., Pedroso, D., Williams, D. \& Li, L. 2012. Breaking processes in three-dimensional bonded granular materials with general shapes. Computer Physics Communications, 183 (2) $266-277$.

Galindo-Torres, S. A. 2013. A coupled Discrete Element Lattice Boltzmann Method for the simulation of fluid-solid interaction with particles of general shapes. Computer Methods in Applied Mechanics and Engineering 265, 107-119.

Gentier, S., Rachez, X., Peter-Borie, M. \& Blaisonneau, A. 2012. Hydraulic stimulation of geothermal wells: Modeling of the hydro-mechanical behavior of a stimulated fractured rock mass. Harmonising Rock Engineering and the Environment - Qian, Q. and Zhou, Y. (Eds). Taylor \& Francis Group, London.

Ghani, I., Koehn, D., Toussaint, R. \& Passchier, C. W. 2013. Dynamic Development of Hydrofracture. Pure Appl. Geophys. , 170 (2013), 1685-1703.

Ghorashi, S. S. \& Monghad, L. 2015. Numerical simulation of fracture reservoir with considering effect of faults in fracture creation in an iranian oil field. Petroleum and Coal 57 (4), 382-388.

Goren, L., Aharonov, E., Sparks, D. \& Toussaint, R. 2010. Pore pressure evolution in deforming granular material: A general formulation and the infinitely stiff approximation. Journal of Geophysical Research, 15, B09216. 
Goren, L., Aharonov, E., Sparks, D. \& Toussaint, R. 2011. The mechanical coupling of fluid-filled granular material under shear. Pure Appl. Geophys. , 168 (2011), 2289-2323.

Guo, F., Morgenstern, N. R. \& Scott, J. D. 1993. Interpretation of hydraulic fracturing breakdown pressure. International Journal of Rock Mechanics and Mining Sciences \& Geomechanics Abstracts, 30, 617-626.

Guo, J.-C., Luo, B., Zhu, H.-Y., Yuan, S.-H., Deng, Y., Duan, Y.-J., Duan, W.-G. \& Chen, L. $2016 a$. Multilayer stress field interference in sandstone and mudstone thin interbed reservoir. Journal of Geophysics and Engineering, 13 (2016), 775-785.

Guo, L., Xiang, J., Latham, J.-P. \& Izzuddin, B. 2016b. A numerical investigation of mesh sensitivity for a new three-dimensional fracture model within the combined finite-discrete element method. Engineering Fracture Mechanics, 151, 70-91.

Hantschel, T. \& Kauerauf, A. I. 2009. Fundamentals of Basin and Petroleum Systems Modeling, Springer-Verlag, Berlin Heidelberg.

Hazzar, L. \& Nuth, M. 2015. 3D distinct element modeling of mechanical lab tests for unsaturated granular materials. CSCE Annual Conference, Regina, Saskatchewan-Canada, May 27-30, Volume: Paper GEN-234.

Healy, D., Yielding, G. \& Kusznir, N. 2004. Fracture prediction for the 1980 El Asnam, Algeria earthquake via elastic dislocation modeling. Tectonics, 23 (6).

Hecht, M. \& Harting, J. 2010. Implementation of on-site velocity boundary conditions for d3q19 lattice Boltzmann simulations. Journal of Statistical Mechanics: Theory and Experiment 2010 P01018.

Hilley, G. E., Arrowsmith, J. R. \& Amoroso, L. 2001. Interaction between normal faults and fractures and fault scarp morphology. Geophysical Research Letters, 28 (19), 3777-3780.

Hofmann, H., Babadagli, T., Yoon, J. S., Blöcher, G. \& Zimmermann, G. 2016. A hybrid discrete/finite element modeling study of complex hydraulic fracture development for enhanced geothermal systems (EGS) in granitic basements. Geothermics 64, $362-381$.

Holland, M., Urai, J. \& Martel, S. 2006. The internal structure of fault zones in basaltic sequences. Earth and Planetary Science Letters, 248, 301-315.

Holland, M., Van Gent, H., Bazalgette, L., Yassir, N., Strating, E. H. H. \& Urai, J. L. 2011. Evolution of dilatant fracture networks in a normal fault - evidence from $4 \mathrm{~d}$ model experiments. Earth and Planetary Science Letters 304 (3-4), 299-406.

Huang, H., Zhang, F., Callahan, P. \& Ayoub, J. A. 2012. Fluid Injection Experiments in 2D Porous Media. 17: 3.

Itasca Consulting Group 2008. PFC 2D (Particle Flow Code, 2 dimension), version 4.0 user manual. Mineapolis, Minesota.

Kuwata, Y., Takada, S. \& Ivanov, R. 2007. DEM response analysis of buried pipelines crossing faults and proposal for a simplified method to estimate allowable fault displacements. Journal of Seismology and Earthquake Engineering, 8 (4), 195-202. 
Lei, Y., Luo, X., Wang, X., Zhang, L., Jiang, C., Yang, W., Yu, Y., Cheng, M. \& Zhang, L. 2015. Characteristics of silty laminae in Zhangjiatan Shale of southeastern Ordos Basin, China: Implications for shale gas formation. AAPG Bulletin, 99 (4), 661-687.

Liu, Z., Jin, Y., Chen, M. \& Hou, B. 2016. Analysis of non-planar multi-fracture propagation from layered-formation inclined-well hydraulic fracturing. Rock Mech Rock Eng, 49, 1747-1758.

Lu, C., Li, M., Guo, J.-C., Tang, X.-H., Zhu, H.-Y., Yong-Hui, W. \& Liang, H. 2015. Engineering geological characteristics and the hydraulic fracture propagation mechanism of the sand-shale interbedded formation in the Xu5 reservoir. J. Geophys. Eng, 12 (2015), 321-339.

Ma, S. \& Morrow, N., R. 1996. Relationships between porosity and permeability for porous rocks. International Symposium of the Society of Core Analysts, Sept. 8-10. Montpelier, France.

Mahrer, K. D., Aud, W. W. \& Hansen, J. T. 1996. Far-field hydraulic fracture geometry: a changing paradigm. SPE Annual Technical Conference and Exhibition, 6-9 October. Denver, Colorado, U.S.A.

Mallon, A. J. \& Swarbrick, R. E. 2002. A compaction trend for non-reservoir North Sea Chalk. Marine and Petroleum Geology, 19 (5), 527-539.

Megson, J. \& Hardman, R. 2001. Exploration for and development of hydrocarbons in the Chalk of the North Sea: a low permeability system. Petroleum Geoscience, 7 (1), 3-12.

Nordgren, R. P. 1972. Propagation of a vertical hydraulic fracture. Old SPE Journal, 12 (4), 306-314.

Okada, Y. 1992. Internal deformation due to shear and tensile faults in a half-space. Bulletin of the Seismological Society of America, 82 (2), 1018-1040.

Olson, J. E. 2004. Predicting fracture swarms - the influence of subcritical crack growth and the crack-tip process zone on joint spacing in rock. Geological Society, London, Special Publications, 231 (1), 73-88.

Ostermeier, R. M. 2001. Compaction Effects on Porosity and Permeability: Deepwater Gulf of Mexico Turbidite. Journal of Petroleum Technology, 53 (2), 68-74.

Peacock, D. C. P. 2001. The temporal relationship between joints and faults. Journal of Structural Geology 23 (2001) 329-341.

Philipp, S., Gudmundsson, A., Meier, S. \& Reyer, D. 2009. Field studies and numerical models of hydrofracture propagation layered fractures reservoirs. Geophysical Research Abstracts, 11.

Pollard, D. D. 1973. Derivation and evaluation of a mechanical model for sheet intrusions. Tectonophysics, 19 (3), 233-269.

Pollard, D. D. \& Muller, O. H. 1976. The effect of gradients in regional stress and magma pressure on the form of sheet intrusions in cross section. Journal of Geophysical Research, 81 (5), 975984.

Potyondy, D. O. \& Cundall, P. A. 2004. A bonded-particle model for rock. International Journal of Rock Mechanics and Mining Sciences, 41, 1329-1364.

Pournin, L. \& Liebling, T. 2005. A generalization of distinct element method to tridimensional particles with complex shapes. Powders \& Grains 2005, Balkema, Leiden, 1375-1478. 
Rawnsley, K. D., Peacock, D. C. P., Rives, T. \& Petit, J. P. 1998. Joints in the Mesozoic sediments around the Bristol Channel Basin. Journal of Structural Geology, 20 (12), 1641-1661.

Rawnsley, K. D., Rives, T., Petti, J. P., Hencher, S. R. \& Lumsden, A. C. 1992. Joint development in perturbed stress fields near faults. Journal of Structural Geology, 14 (8), 939-951.

Schopfer, M. P. J., Childs, C., Manzocchi, T. \& Walsh, J. J. 2016. Three-dimensional Distinct Element Method modelling of the growth of normal faults in layered sequences. In Childs, C., Holdsworth, R. E., Jackson, C. A.-L., Manzocchi, T., Walsh, J. J. \& Yielding, G. (eds), The Geometry and Growth of Normal Faults. Geological Society, London, Special Publications, 439.

Schopfer, M. P. J., Childs, C. \& Walsh, J. J. 2007a. Two-dimensional distinct element modeling of the structure and growth of normal faults in multilayer sequences: 1 . Model calibration, boundary conditions, and selected results. Journal of Geophysical Research, 112, B10401.

Schopfer, M. P. J., Childs, C. \& Walsh, J. J. 2007b. Two-dimensional distinct element modeling of the structure and growth of normal faults in multilayer sequences: 2. Impact of confining pressure and strength contrast on fault zone growth and geometry. Journal of Geophysical Research, 112, B10404.

Secor Jr, D. T. \& Pollard, D. D. 1975. On the stability of open hydraulic fractures in the Earth's crust. Geophysical Research Letters, 2 (11), 510-513.

Shakib, J. T., Ghaderi, A., Akhgarian, E. \& Torfi, M. 2013. Analysis of hydraulic fracture propagation in fractured reservoirs: fracture coalescence and reverse suction two important parameters the interaction between induced and natural fractures. World Applied Sciences Journal 28 (11), $1585-1591$.

Shepherd-Thorn, E. R. 1988. Geology of the country around Ramsgate and Dover. Memoir of the British Geological Survey, Sheets 274 and 290 (England and Wales).

Shimizu, H., Murata, S. \& Ishida, T. 2011. The distinct element analysis for hydraulic fracturing in hard rock considering fluid viscosity and particle size distribution. International Journal of Rock Mechanics and Mining Science \& Geomechanics 48, 712-727.

Simonson, E. R., Abou-Sayed, A. S. \& Clifton, R. J. 1978. Containment of massive hydraulic fractures. Spe Journal, 18 (1), 27-32.

Singhal, B. B. S. \& Gupta, R. P. 2010. Applied Hydrogeology of Fractured Rocks. 2nd Edition, Netherlands, Springer.

Souque, C., Knipe, R. J., Davies, R. K., Jones, P., Welch, M. J. \& Lorenz, J. (in review). Fracture corridors and fault reactivation: Example from the Chalk, Isle of Thanet, Kent, England.

Sperl, J. \& Trckova, J. 2008. Permeability and porosity of rocks and their relationship based on laboratory testing. Acta Geodyn. Geomater, 5 (1), 41-47.

Tarokh, A., Blanksma, D. J., Fakhimi, A. \& Labuz, J. F. 2016. Fracture initiation in cavity expansion of rock. International Journal of Rock Mechanics \& Mining Sciences, 85, 84-91.

Tiegang, F., Guangqing, Z. \& Jinbang, C. 2014. The impact of cleats on hydraulic fracture initiation and propagation in coal seams. Pet. Sci., 11, 532-539. 
Tomac, I. \& Gutierrez, M. 2017. Coupled hydro-thermo-mechanical modeling of hydraulic fracturing in quasi-brittle rocks using BPM-DEM. Journal of Rock Mechanics and Geotechnical Engineering, 9 (1), 92-104.

Urai, J. L., Kettermann, M., Abe, S. \& Virgo, S. 2016. Aspects of fault zones around the Rotliegend reservoirs and the possible effects of salt in the fault zones on rates of seismicity in these zones. Report on a project supervised by ir J.P.A. Roest, State Supervision of Mines, Ministerie van Economische Zaken, Henri Faasdreef, Den Haag.

Van Gent, H. W., Holland, M., Urai, J. L. \& Loosveld, R. 2010. Evolution of fault zones in carbonates with mechanical stratigraphy - insights from scale models using layered cohesive powder. Journal of Structural Geology 32 (9), 1375-1391.

Vinningland, J. L., Johnsen, Ø., Flekkøy, E. G., Toussaint, R. \& Maløy, K. J. 2007. Granular Rayleigh-Taylor Instability: Experiments and Simulations. Physical Review Letters, 99, 048001 .

Wang, Y. \& Adhikary, D. Hydraulic Fracture Simulation Based on Coupled Discrete Element Method and Lattice Boltzmann Method. Proceedings World Geothermal Congress, 19-25 April, 2015 Melbourne, Australia.

Wang, Y., Li, X., He, J., Z., Z. \& Zheng, B. 2016. Investigation of fracturing network propagation in random naturally fractured and laminated block experiments. Energies, 9, 588.

Wang, Y. C., Wang, S. M., Xue, S. \& Adhikary, D. 2015. Numerical modeling of porous flow in fractured rock and its applications in geothermal energy extraction. Journal of Earth Science, 26 (1), 20-27.

Weertman, J. 1971. Theory of water-filled crevasses in glaciers applied to vertical magma transport beneath oceanic ridges. Journal of Geophysical Research, 76 (5), 1171-1183.

Welch, M. J., Souque, C., Davies, R. K. \& Knipe, R. J. 2015. Using mechanical models to investigate the controls on fracture geometry and distribution in chalk. Geological Society, London, Special Publications, 406, 281-309.

Witherspoon, P. A., Wang, J. S. Y., Iwai, K. \& Gale, J. E. 1980. Validity of cubic law for fluid flow in a deformable rock fracture. Water Resources Research, 16, 1016-1024.

Xu, Y., Dai, F., Xu, N. W. \& Zhao, T. 2016. Numerical Investigation of Dynamic Rock Fracture Toughness Determination Using a Semi-Circular Bend Specimen in Split Hopkinson Pressure Bar Testing. Rock Mech Rock Eng, 49, 731-745.

Yang, Y. \& Zoback, M. D. 2014. The role of preexisting fractures and faults during multistage hydraulic fracturing in the Bakken Formation. Interpretation, 2 (3), SG25-SG39.

Yushi, Z., Shicheng, Z., Tong, Z., Xiang, Z. \& Tiankui, G. 2016. Experimental investigation into hydraulic fracture network propagation in gas shales using CT scanning technology. Rock Mech Rock Eng, 49, 33-45.

Zhang, F., Damjanac, B. \& Huang, H. 2013. Coupled discrete element modeling of fluid injection into dense granular media. Journal of Geophysical Research: Soild Earth, 118, 2703-2722.

Zhang, G. \& Fan, T. 2016. Laboratory investigations of hydraulic fractures in naturally fractured formations. In: Alves, L. M. (ed.) Fracture Mechanics - Properties, Patterns and Behaviours. Croatia: Intech. 
Zhao, J. \& Shan, T. 2013. Coupled CFD-DEM simulation of fluid-particle interaction in geomechanics. Powder Technology 239, 248-258.

Zhou, J., Huang, H. \& Deo, M. 2016. Simulation of hydraulic and natural fracture interaction using a coupled DFN-DEM model. ARMA 50th US Rock Mechanics / Geomechanics Symposium, 2629 June. Houston, Texas, U.S.A.

Zimmerman, R. W. \& Bodvarsson, G. S. 1996. Hydraulic conductivity of rock fractures. Transport in Porous Media, 23, 1-30.

\section{Appendices}

\section{A1.1 Particle Flow Model}

The model is made up of an assembly of randomly sized and arbitrary shaped particles that are rigid (non-deformable) and only interacting with other particles at interfaces or at the point of contact between them (Eshiet and Sheng, 2011). The concept of particles as defined here is different from 
conventional definition given in solid mechanics where a particle is regarded as a body with a negligible size, occupying a single point. The definition of a particle in DEM refers to a body which occupies a finite amount of space and interacts with other particles via contacts. These particles are also allowed to displace independently from each other. Where the particles are assumed to be rigid, the mechanical behaviour of an assembly of particles can be predicted through the displacement and overlapping of these particles as well as the inter-particle contact forces. Each contact has distinctive properties such as normal and shear stiffnesses and contact forces. Material deformation is modelled through the sliding and rotation of the particles, as well as the opening and interlocking of particle at interfaces.

It should be noted that these particles do not directly represent the grains in the rock. Rock grains, especially in a fine-grained rock, are sufficiently small that it would be impractical to represent individual rock grains as discrete particles in a model of this scale.

Particle motion is allowed to occur independently. The characteristics of the system are described strictly in terms of the mechanical behaviour governed by motion of particles and the forces generated at contacts between particles. To enable this process, Newton's law of motion is used to relate particle motion with forces generated at inter-particle contacts. For bulk (non-granular) materials, cementation of particles is allowed by introducing the concept of bonding between particles such that when the bond strength are exceeded, breakages occur thereby freeing the particle. Generated particles are regarded to be circular; however, the clump logic (Cho et al., 2007) can be used to create arbitrary shaped rigid particles that are deformable at the boundaries.

To mimic rock materials each model consists of an assembly of particles bonded together at such strength and stiffness that will permit a mechanical behaviour similar to actual rocks. Although the clump logic can be employed to generate irregularly shaped particles, individual particles used for this work were generated as circular. The emphasis was to replicate the micro-mechanical behaviour of rocks, which is mainly controlled by the initiation, growth and interaction of microcracks (Potyondy and Cundall, 2004). Formation of cracks takes place when the normal and shear bond between particles are exceeded resulting in a disconnection of previously attached particles. Depending on the type of broken bond, either a tensile or shear crack is formed. Continuous generation and linkages of individual micro-cracks leads to the development of fractures. The phenomenon mentioned above and the implementation of the principles is done through a DEM (Distinct Element Method) code and a PFC (Particle Flow Code), whereby a time stepping algorithm that implies the repeated invocation of the law of motion and the force-displacement law is called. Newton's law of motion is used to control the movement of particles while a force-displacement law determines the current contact forces occurring as a result of the motion of particles at the respective contact. 
Particle behaviour is thus governed by two basic laws: The law of Force-Displacement, and law of Motion. The Force-Displacement law defines the contact force between two entities in terms of their stiffness and the relative displacement between the entities (Figure 2). The formulations for the contact forces are illustrated in Itasca Consulting Group (2008) and Eshiet and Sheng (2011), in which the forces are resolved into normal and shear components. Further illustrations of the DEM technique can also be accessed through Hazzar and Nuth (2015) and Potyondy and Cundall (2004).
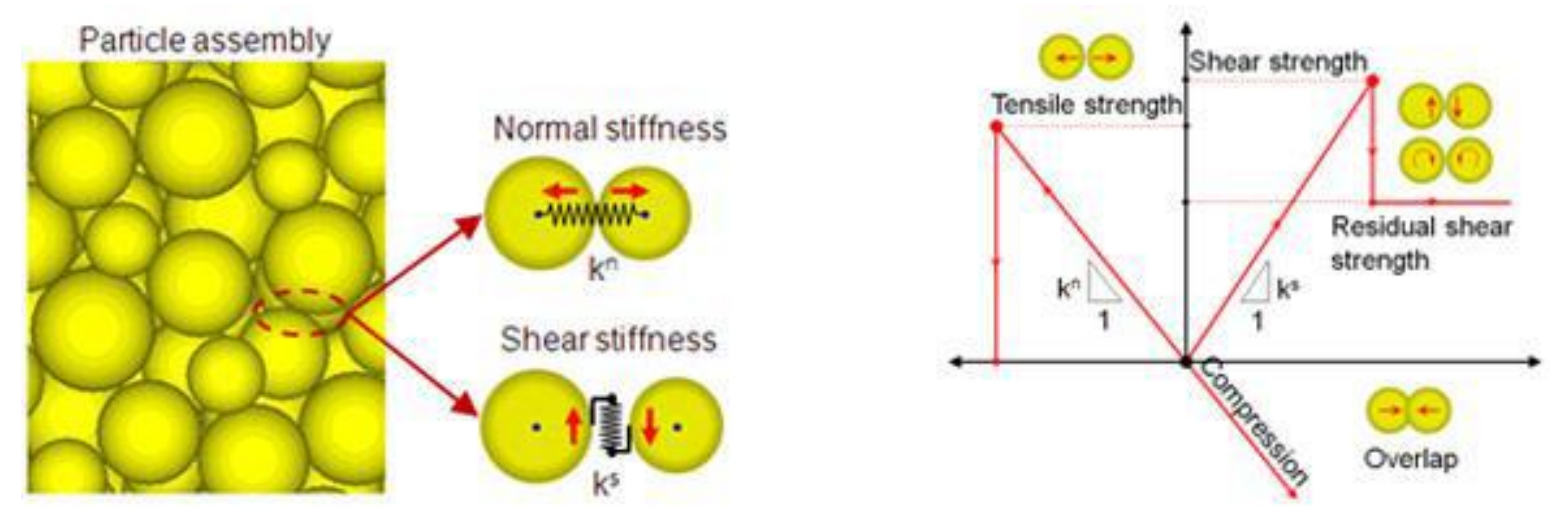

Figure 2 Particle assembly (left) showing the linear contact model (right) (Hazzar and Nuth, 2015)

\section{A1.2 Fluid flow scheme}

In the algorithm the evolution of porosity is implicitly modelled using changes in aperture sizes. It is assumed that the matrix of particles remain coherent. The sample is calibrated to have an intrinsic permeability related to a given value of residual aperture. Values of the residual aperture change depending on whether compressive or tensile forces are dominant. Accordingly, the material permeability changes since it is linked to the aperture size. The permeability is influenced by the microstructure described in terms of the existence of pores spaces and cracks, which means that an increase in porosity is expected as permeability increases (Sperl and Trckova, 2008). However other factors including the pore structure and mineral composition of the rock material also affect the permeability. The Kozeny Carman equation (Ma and Morrow, 1996, Dullien, 1992, Bear, 1979) is an example of a relationship that relates permeability to porosity and particle size.

The description of the fluid flow implementation technique as presented in Eshiet and Sheng (2011) is reiterated. The fluid flow algorithm assumes the presence of voids between particles, which may or may not be filled with fluid (Figure 3). Where particles are in contact, the 2D calculation assumes a no flow condition at the contacts between particles. This implies that for flow to occur between 
domains there must be an opening, hereby referred to as aperture between particles in contact. Domains are created which are in a loose sense representative of voids surrounded by particles. This is achieved by drawing lines between the centres of contacting particles, thereby creating enclosures (referred to as domains); the centres of these domains are registered as reservoirs, with each reservoir connected by pipes, and each pipe representing a particle contact (Itasca Consulting Group, 2008, AlBusaidi et al., 2005).

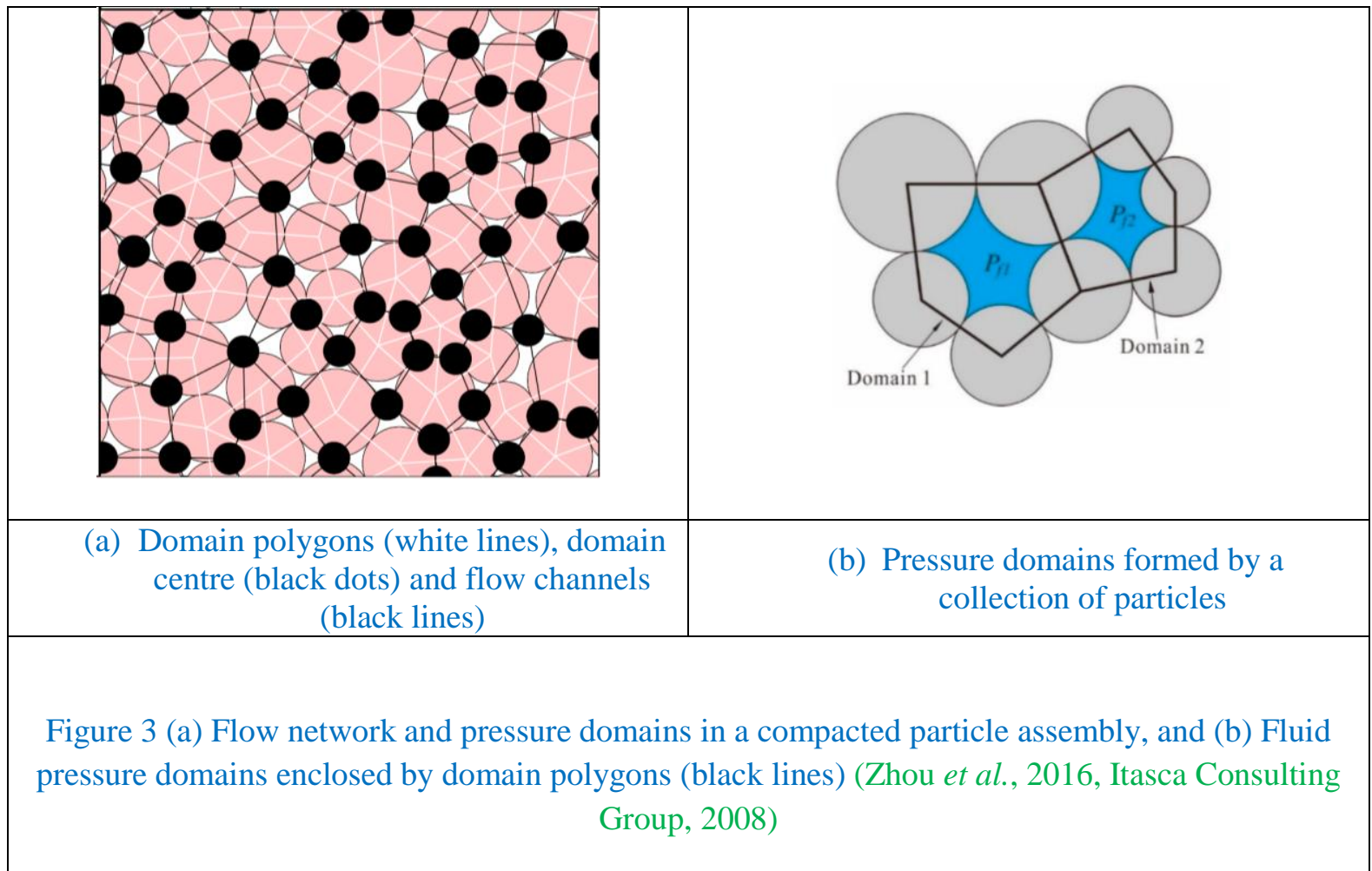

The pathway for flow between domains occurs at contacts through parallel-plate channels. By assigning values for the aperture, fluid flow between domains can be controlled, and is modelled based on the cubic law for flow and the Parallel Plate Model used to model conductivity within fractures (Zimmerman and Bodvarsson, 1996, Witherspoon et al., 1980). It can be considered to be a modified form of the Poiseuille equation due to broad similarities in features. The flow rate across each parallel-plate channel is given as (Shimizu et al., 2011, Al-Busaidi et al., 2005, Zimmerman and Bodvarsson, 1996, Witherspoon et al., 1980):

$$
Q_{p}=\frac{w a^{3}}{12 \mu} \frac{\Delta P}{L_{p}}
$$


Where, $w$ is the channel width given as a unit thickness, $a$ is the aperture, $\Delta P$ is the pressure differential between the pair of domains, $L_{p}$ is the assumed length of the channel taken as the harmonic mean of size of particles forming the contact; and $\mu$ is the fluid viscosity. An out of plane thickness of one is assumed for 2D modelling. The channel length is calculated by (Shimizu et al., 2011):

$$
L_{p}=\frac{4 r_{1} r_{2}}{r_{1}+r_{2}}
$$

Where, $r_{1}$ and $r_{2}$ is the radius of the pair of particles in contact. To account for the material intrinsic permeability, a residual aperture value is assigned, which is the aperture size at bonded contacts at the no load condition; diminishing asymptotically to zero with increasing compressive forces. An empirical expression that relates the aperture to the compressive forces is (Itasca Consulting Group, 2008):

$$
a=\frac{a_{o} F_{o}}{F+F_{o}}
$$

Where, $a_{o}$ is the residual aperture; $F_{o}$ is the compressive force at which the residual aperture reduces to half its size, (i.e. $a_{0} / 2$ ); while $F$ is the updated current compressive force. If $F_{o}$ is set to a large value in comparison to generated contact forces, the aperture size remains equal to its residual value. Where there is no normal force (tensile or compressive), the aperture size is the same as the residual aperture or equal to the sum of the residual aperture and the gap between the surfaces of contacting pair of particles. For the latter case, a multiplier factor $(\beta)$ may be included to control the magnitude of the distance between particles $(\hat{d})$. This may be necessary during calibration since the particle sizes used in most models are often larger than real grains. Hence, if the normal force is tensile or equal to zero, the aperture is given as:

$$
a=a_{0}+\beta \hat{d}
$$


The pressure formulation for each domain is such that the perturbations are as a result of the inflow or outflow of fluid from the connecting channels that make up the domain. Fluid pressure and volume at each domain are updated during every fluid cycle, and the effect of the fluid pressure is experienced as body forces on domain particles. If inflow is assumed to be positive, the change in pressure, $\Delta P$ can be calculated if the following is known: the net sum of inflow from enclosing channels, $\sum Q$; the apparent volume of the domain (reservoir), $V_{d}$; the timestep, $\Delta t$; and the fluid bulk modulus, $K_{f}$. The relation is expressed as:

$$
\Delta P=\frac{K_{f}}{V_{d}}\left(\sum Q \Delta t-\Delta V_{d}\right)
$$

Pressure exerted on particles by fluid in the domain allows a complete coupling of the fluid-solid interaction. Fluid pressure exerted causes deformation and displacement of particles. In return, displacement of particles alters the contact forces that are used to update the aperture size. Fluid-solid coupling is done via: changes in aperture as a result of contact forces; changes in domain pressures as a result of changes in sizes of domain; and the exertion of domain pressure on surrounding particles.

For each flow pipe, the flow rate, $Q_{p}$ is calculated using Equation A1. Therefore, for a given volume of sample, $V$, the flow rate (discharge) is determined as (Al-Busaidi et al., 2005):

$$
Q=\frac{1}{V} \sum Q_{p} V_{p}
$$

Where, $V_{p}$ is the volume of flow pipe. The algorithm adopted in the fluid scheme assumes the sample is fully saturated. That is, $S=1$. Hence, the amount of fluid contained in the domain is equal to the domain volume. The flow rate determine by Equation A6 can be equated to the flow of fluid through a porous medium given by Darcy's law, expressed as:

$$
Q=\frac{k A}{\mu} \frac{\Delta P}{L}
$$


Where, $k$ is the intrinsic permeability of the material; $A$, the cross-sectional area of the sample; $\Delta P$, the pressure differential; $\mu$, the fluid viscosity; and $L$, the sample length.

\section{A1.3 Calibration of fluid flow properties}

The intrinsic permeability $k$ is a macroscopic parameter. By combining Equations A1, A6 and A7), an expression for $k$ can be derived which should be comparable in value to measured permeability values. Combining Equation A1 and A6, the following is obtained (Eshiet and Sheng, 2011):

$$
\begin{aligned}
& \frac{a^{3} \Delta P}{12 \mu L}=\frac{1}{V} \sum Q_{p} V_{p} \\
& \Delta P=\frac{12 \mu L}{a^{3} V} \sum Q_{p} V_{p}
\end{aligned}
$$

From Equation A7

$$
\begin{aligned}
Q & =\frac{k A \Delta P}{\mu L}=\frac{k A}{\mu L}\left(\frac{12 \mu L}{a^{3} V} \sum Q_{p} V_{p}\right) \\
& =\frac{12 k A}{a^{3} V} \sum Q_{p} V_{p}
\end{aligned}
$$

In 2D, $V=L H$ and $A=H$. Where, $V$ is the volume and $A$ is the cross-sectional area. Equation A9 is rewritten as

$$
\begin{gathered}
Q=\frac{12 k H}{a^{3} L H} \sum Q_{p} V_{p} \\
=\frac{12 k}{a^{3} L} \sum Q_{p} V_{p} \\
k=\frac{a^{3} Q L}{12 \sum Q_{p} V_{p}}
\end{gathered}
$$

From Equation A6 


$$
\begin{gathered}
Q V=\sum Q_{p} V_{p} \\
k=\frac{a^{3} Q L}{12 Q V}=\frac{a^{3} Q L}{12 Q L H}
\end{gathered}
$$

Therefore

$$
k=\frac{a^{3}}{12 H}
$$

For a given value of $\mathrm{H}$ and calibrated value of $a, k$ is equivalent to the macroscopic permeability. A steady state flow test (permeability test) is required whereby simulation of fluid flow through the sample is continued until a steady state condition is achieved. An indication of a steady state condition is when the flow rate at the inlet, $Q_{i}$ is equal to the flow rate at the outlet, $Q_{o}$. The residual aperture, $a_{0}$ directly influences the intrinsic macroscopic permeability, and as such is adjusted to obtain target values. 